\title{
PERSONALITY TRAITS AND STOCK MARKET PARTICIPATION
}

Andrew Conlin ${ }^{\mathrm{a}}$, Petri Kyröläinen ${ }^{\mathrm{b}}$, Marika Kaakinen ${ }^{\mathrm{c}, \mathrm{d}}$, Marjo-Riitta Järvelinn ${ }^{\mathrm{c}, \mathrm{e}, \mathrm{f}}$, Jukka Perttunenª, Rauli Svento $^{g}$

\section{Abstract:}

We analyze the relationship between personality traits and stock market participation. Our sample comes from combining personality trait scores and socioeconomic status information from the Northern Finland Birth Cohort 1966 with data from Finnish Central Securities Depository, the official register of stock holdings in Finland. We find the traits, and especially the subscales of the traits, to be significant predictors of stock market participation. In particular, exploratory excitability, extravagance, sentimentality, and dependence have large effects. One-standard-deviation changes in the subscale scores have marginal effects of up to 4 percentage points on the probability of participating in the stock market.

Keywords: stock market participation; personality; temperament

JEL classification: G02, G11

Author affiliations:

aDepartment of Finance, Oulu Business School, University of Oulu, Oulu, Finland

${ }^{b}$ Oulu Business School, Oulu, Finland

'Institute of Health Sciences and Biocenter Oulu, University of Oulu, Oulu, Finland

${ }^{\mathrm{d}}$ Department of Genomics of Common Disease, Imperial College London, London, United Kingdom

eDepartment of Life Course and Services, National Institute for Health and Welfare, Oulu, Finland

${ }^{\mathrm{f}}$ Department of Epidemiology and Biostatistics, MRC-HPA Centre for Environment and Health, Imperial College London, London, United Kingdom

'Department of Economics, Oulu Business School, University of Oulu, Oulu, Finland

We thank Markku Kaustia, Antti Lehtoranta, and GSF workshop participants for helpful comments. We thank late Professor Paula Rantakallio (launch of NFBC1966 and initial data collection), Ms Sarianna Vaara (data collection), Ms Tuula Ylitalo (administration) and Mr Markku Koiranen (data management). We also thank the editor and two anonymous referees for helpful comments.

This work was supported by the Academy of Finland [project grants 104781, 120315, 129418, Center of Excellence in Complex Disease Genetics and Public Health Challenges Research Program (SALVE)], University Hospital Oulu, Biocenter, University of Oulu, Finland (75617), the European Commission [EUROBLCS, Framework 5 award QLG1-CT-2000-01643], EU Framework Programme 7

[EurHEALTHAgeing (277849)], The National Heart, Lung and Blood Institute [5R01HL087679-02] through the SNP Typing for Association with Multiple Phenotypes from Existing Epidemiologic Data (STAMPEED) program [1RL1MH083268-01], The National Institute of Health/The National Institute of Mental Health [5R01MH63706:02], European Network of Genomic and Genetic Epidemiology (ENGAGE) project and grant agreement [HEALTH-F4-2007-201413], and the Medical Research Council, UK [G0500539, G0600705, PrevMetSyn/Public Health Challenges Research Program (SALVE)]. Andrew Conlin thanks OP-Pohjola Tutkimussäätiö and the Graduate School of Finance (GSF) for generous support.

Corresponding author: Andrew Conlin, Oulu Business School, P.O. Box 4600, 90014 Oulu, Finland. email: andrew.conlin@oulu.fi phone: +358294487786 


\section{Introduction}

Behavioral finance is making progress in exploring and explaining the reasons behind investor heterogeneity. The classical assumption is that investors vary only in their levels of wealth and risk aversion. Many works in the field of behavioral finance have shown other factors also affect investment decisions (e.g. Barber and Odean (2001), Kamstra et al. (2003), Grinblatt et al. (2011)). The first decision regarding investing that an individual makes, however, is whether to actually be an investor or not. With regards to investments in the stock market, prior work has shown that differences in wealth and risk aversion do not adequately explain individuals' decisions to invest or not. In this paper, we use personality traits to help explain the decision to participate in the stock market.

We combine two data sets to create a sample that allows us to closely examine the relationship between personality traits and stock market participation while controlling for many of the factors known to affect the participation decision. The Northern Finland Birth Cohort 1966 (NFBC1966) has been actively following cohort members' physical health, mental health, and socioeconomic status since the members' birth in 1966. From a survey collected when cohort members were 31 years old, we have personality data and socioeconomic variable observations for over 3000 individuals. The personality traits of the individuals are assessed with Cloninger et al.'s (1993) Temperament and Character Inventory (TCI). The stock market participation data comes from the Finnish Central Securities Depository (FCSD), the official register for stock holdings in Finland. The combination of the NFBC1966 and FCSD data gives us a large sample with detailed personality trait information, a good list of control variables, and official stock holdings data. The sample is thus well-suited to analyzing the personality-stock market participation question.

The results show that personality traits help explain stock market participation. Most of the mean scores for the personality traits and trait subscales are significantly different between participants and nonparticipants. We perform logistic regression analyses to quantify the effect of the traits on stock market participation while controlling for gender, income, family status, education, and occupation. For example, a one standard deviation increase in the score for the trait harm avoidance, which is exemplified by behavioral inhibition, reduces the probability of participation by 2 percentage points. The unconditional probability of participation for the sample is 0.17 , implying a large effect. 
We also show that the subscales (also known as trait facets) offer more insight into the effects of personality on participation. Novelty seeking has a subscale, extravagance, which has an effect on participation opposite to the other novelty seeking subscales. The effect of extravagance is large and negative, and this effect was otherwise hidden when using the trait novelty seeking; two other novelty seeking subscales, exploratory excitability and impulsiveness, have a positive effect on stock market participation. Another example is the contrasting effects of sentimentality and dependence, two subscales of the trait reward dependence. Among a subsample of high socioeconomic status individuals, higher sentimentality scores reduce stock market participation, while higher dependence scores increase stock market participation.

We perform additional tests to support the claim that personality affects stock market participation. We run univariate logistic regressions for the traits and the subscales, both without and with controls, to address any multicollinearity problems between the traits and the controls and between the subscales themselves. The univariate regressions support the results found in the regressions using multiple traits. Generally, the effects are of the same size and statistical significance, providing further evidence of the relationship between personality and stock market participation. In a separate test, we find those subscales which are positively related to participation have the exact opposite effect when it comes to the decision to exit the market. We also check the influence of Nokia on our sample; we find that holdings of Nokia are unlikely to have influenced our results, despite it being the dominant stock in Finland over most of our sample period.

There is a high probability that the traits and subscales are predictors of some of the controls, especially educational achievement and occupation. However, when we look at a subsample of high socioeconomic status individuals (those individuals with a university degree and a managerial level occupation), we find the subscales exploratory excitability, extravagance, sentimentality, and dependence to be significantly related to participation while still controlling for gender and income. In this subsample, a one standard deviation change in any of these subscales changes the probability of being a stock market participant by 7-10 percentage points. We do not have observations for wealth, but it is likely that those individuals who have both a university degree and a managerial level education generally have a higher 
wealth level. The significance of the personality subscales in this subsample offers good evidence that personality traits can help explain stock market participation even among the wealthy.

We are able to control for many investor characteristics that are likely to affect the participation decision, but we do not have a direct measure of risk aversion. While standard theory predicts a positive share of wealth held in stocks even for the very risk averse (as long as the equity premium is positive), for most people high levels of risk aversion will mean staying out of the market. The trait harm avoidance can be viewed as a proxy for risk aversion. In particular, the subscale fear of uncertainty is a good measure of general risk aversion. Ekelund et al. (2005) used fear of uncertainty as a proxy for risk aversion when looking at the decision to be self-employed. Fear of uncertainty measures more the domain of general risk taking as opposed to financial risk taking, but prior works have shown general risk taking to be a good predictor of stock market investing (Halko et al. (2012); Dohmen et al. (2011)).

Prior work on factors related to stock market participation include pecuniary costs (Vissing-Jørgensen (2003)), awareness (Guiso and Jappelli (2005)), and financial literacy (Van Rooij et al. (2011)). Being more social may lower the cost of investing and increase stock market participation (Hong et al. (2004)). The portfolio performance of one's social acquaintances is positively related to stock market participation (Kaustia and Knüpfer (2012)). Personal beliefs, such as trust in others (Guiso et al. (2008)) and political ideology (Kaustia and Torstila (2011)) affect stock market participation. Cognitive ability (Cole and Shastry (2009), Christelis et al. (2010), Grinblatt et al. (2011)) has a clear effect on stock market participation. Dimmock and Kouwenberg (2010) use loss aversion from prospect theory (Kahneman and Tverskey (1979)) to show that individuals that are more loss averse are less likely to participate in the stock market.

We argue that personality traits should be on this list of factors. Some earlier research in economics and finance has used the 'Big Five' personality traits openness to experience, conscientiousness, extraversion, agreeableness, and neuroticism (see e.g. McCrae and Costa, 1997). Ameriks et al. (2009) find the 'Big Five' traits are related to investment decisions by retirement account holders. Brown and Taylor (2011) also use the Big Five personality traits and find that some of the traits influence holding stocks and other financial assets. Our study is closest to that of Brown and Taylor (2011), but is distinguished in a few meaningful ways. We use Cloninger et al.'s (1993) TCI temperament traits and not the Big Five. We have scores for the traits and subscales, offering a more detailed look at the personality - stock market 
participation relationship. Our cohort members are all the same age, eliminating the influence of age on the personality traits and other variables across individuals.

The Big Five model has been used more than the TCI in many disciplines, including medicine, psychology, economics, and finance. ${ }^{1}$ The main difference between the two is the origin of the models: the TCI is theoretically based on neurotransmitter systems in the brain, giving it testable predictions regarding its physiological basis; the Big Five essentially come from condensing a large set of adjectives used to describe individuals, without any true theory underlying the origin of the traits. While the two models differ in their theoretical foundations and traits, there is a general correlation of the traits across the models and both have been shown to be useful in research. Almlund et al. (2011) and Borghans et al. (2008) mention the TCI as an alternative to the Big Five model of personality. For a direct comparison of the two models, see De Fruyt et al. (2000); see Markon et al. (2005) for a look at several widely used personality models, including the TCI and the Big Five.

To our knowledge, the only paper using the TCI that has been published in a finance or economics journal is Ekelund et al. (2005), which looks at factors affecting the choice to be self-employed, using a subscale of harm avoidance as a proxy for risk aversion. Even though the TCI has not been used as much in finance or economics, it has been used widely in psychiatry and medicine. A few examples of use of the TCI for predicting behavior often of interest to economists include: smoking and drinking (Wills et al. (1994), Cloninger et al. (1988)); drug addiction (Milivojevic et al. 2012); and gambling (Martinotti et al. 2006).

Our paper's main contribution is to show that personality traits have strong effects on stock market participation. For example, changes of one standard deviation in the trait scores are associated with changes of up to 4 percentage points in the probability of participation; for a subsample of individuals with higher education and occupational status, the effects are up to 10 percentage points. We show that trait scores may not reveal the true relationship between personality and stock market participation, as the subscales of a trait may have opposing effects on participation. We show the effects of personality traits on stock market participation are consistent over time and across model specification, supporting the argument for including personality in finance and economic research.

\footnotetext{
${ }^{1}$ We speculate that one reason the TCI is not used as much is its length. The shortest version for adults has 140 questions (our subjects answered the 107 temperament questions from the 240 item TCI version 9), while there are versions of the Big Five that have as few as 10 questions (see e.g. Gosling et al. (2003)).
} 
The importance of personality traits to understanding stock market participation is twofold. Firstly, the more we know about individual heterogeneity, the better we will be able to model behavior. As we demonstrate below, personality traits help to explain nonparticipation even amongst the wealthy and welleducated members of our sample. Secondly, personality trait differences may limit the impact of policy: improved education, tax incentives, or market regulation may not work as intended if personality differences have a strong effect on behavior.

The rest of the paper is structured as follows. Section 2 gives more detail on the TCI and our expectations of the relationship between the traits and stock market participation. Section 3 describes our data and presents the sample descriptive statistics. Section 4 provides results and Section 5 concludes.

\section{Personality and Stock Market Participation}

Personality psychology encompasses a wide range of individual differences, such as traits, abilities, motives, and intelligence. This paper focuses on personality traits. Personality traits describe our typical behavioral and emotional responses to the world around us. Of course, the situations we face in the world are constantly changing and our responses to these situations are not mechanical. However, personality trait theory attempts to capture and measure our repeated behaviors and thoughts in contextually similar situations. ${ }^{2}$ In this paper, the stock market is the common stimuli for all of the individuals in our sample, and their gender, education, family status, and employment status help to contextualize the stock market individual situation. By controlling for these other factors, we are able to get a good measure of the effect of personality traits on stock market participation. ${ }^{3}$

\subsection{Descriptions of the TCI Traits and Subscales}

We use the temperament traits from the Temperament and Character Inventory (version IX) of Cloninger et al. (1993), which arose from the original model of Cloninger (1987). This model uses the term temperament because the traits are theorized to have a biological basis in separate neurotransmitter systems in the brain. As these neurotransmitter systems are physical entities, the model loosely implies that we are

\footnotetext{
${ }^{2}$ See Roberts (2009) for a good discussion on personality traits and the trait-situation debate.

${ }^{3}$ For further insight into the possible role personality plays in economic decision making and economic research, see Almlund et al. (2011).
} 
"hard-wired" for our temperament traits. The traits thus provide a measure of how strongly we instinctually respond to various stimuli. ${ }^{4}$

Cloninger (1987) developed his model in an attempt to reconcile two issues within personality theory: the dimensions of normal personality traits did not fit well with the recognized categories of personality disorder at the time; and the underlying biological sources of personality were not well understood, confounding medical treatment for personality disorders (p. 574). Cloninger's original model was composed of three personality traits, novelty seeking, harm avoidance, and reward dependence, each based on a specific brain structure. Novelty seeking is based on the dopamine pathway in the brain. Increased levels of dopamine are associated with feelings of pleasure and behavioral activation. Harm avoidance is based on the serotonin pathway, which is associated with behavioral inhibition. Reward dependence is based on the noradrenergic system, in which norepinephrine is involved with learning and memory. The traits should be normally distributed across the population, with very high or very low levels of one or more of the traits a potential indicator of mental disorder (Cloninger (1987)).

The newer TCI (Cloninger et al. (1993)) builds on the earlier model by adding persistence to the three original traits (persistence was a subscale of reward dependence in the 1987 model). ${ }^{5}$ We briefly describe the traits here. For more detailed descriptions, please see Cloninger et al. (1994). Novelty seeking measures the tendency for behavioral activation and exploration when faced with novel stimuli. Persons high in novelty seeking will actively seek pleasure and rewards, while those with low novelty seeking will be much more reserved. Harm avoidance measures the tendency for behavioral inhibition when faced with danger or punishment. Being nervous or timid is an indicator of high harm avoidance, while being relaxed in potentially harmful situations is a sign of low harm avoidance. Reward dependence measures the tendency to maintain behavior previously rewarded, especially in reference to signals received from other individuals. Persons with high reward dependence scores are often social and interactive with others, while those low in

\footnotetext{
${ }^{4}$ The evidence on the biological factors underlying the model is mixed. Papers linking the neurotransmitters to the traits include: serotonin - Peirson et al. (1999); dopamine - Ebstein et al. (1996); and all three neurotransmitters - Gerra et al. (2000). Works linking genetic variation to the traits include Ebstein et al. (1996) and Melke et al. (2003); Kühn et al. (1999) find results supporting a genetic basis for reward dependence but not novelty seeking. Recent works by Verweij et al. (2010) and Service et al. (2012) do not support a genetic basis for the traits.

${ }^{5}$ The TCI also includes the character dimensions of self-directedness, cooperativeness, and self-transcendence. The character dimensions reflect how one views oneself in relation to others and the world at large, while the temperament traits reflect habitual, or instinctual, responses to stimuli. We do not have data on the character dimensions, so we refrain from further discussion.
} 
reward dependence often prefer to be alone. Persistence, as the name implies, measures how hard an individual can push herself to achieve her goals.

Our unique data set contains the subscale scores of the personality traits. Novelty seeking and harm avoidance each have four subscales. Reward dependence has three subscales. Persistence does not have any subscales. In terms of measurement, the trait scores are simply the sum of the subscale scores (Cloninger et al. (1994)). From an economic perspective, the subscales offer better descriptions and measurements of an individual's preferences and clearer hypotheses for their relationship with stock market participation than the traits.

The four subscales of novelty seeking divide this general tendency into more specific domains: exploratory excitability, impulsiveness, extravagance, and disorderliness. Individuals with high explorative excitability actively seek new things and get bored easily. Impulsive individuals follow their instincts in search of reward, without contemplation and without worrying about having complete information (Cloninger et al. (1994)). Impulsiveness in the TCI is related to making quick decisions with partial information, while extravagance measures the preference for spending over saving. These definitions differ from some common usages in psychology, with extravagance being closer in meaning to the impulsivity/delayed gratification of Mischel et al. (1989). The extravagance subscale consists of nine statements. Eight of them are explicitly about saving or spending money such as "I am better at saving money than most people" and "Because I so often spend too much money on impulse, it is hard for me to save money - even for special plans like a vacation". The only item which is not explicitly about spending or saving is a self-control related statement "I am more reserved and controlled than most people. Disorderliness reflects the degree to which one dislikes rules or routines (Cloninger et al. (1994)).

Harm avoidance is exemplified by behavior inhibition; when faced with potential punishment, individuals with high harm avoidance will refrain from acting. A loose interpretation would be "cowering in fear" when faced with dangerous situations, whether the situation is truly dangerous or just perceived to be dangerous. The four harm avoidance subscales are worry/pessimism, fear of uncertainty, shyness, and fatigability. Worry/pessimism reflects a generally pessimistic view about the future. Fear of uncertainty captures one's fear of unfamiliar and uncertain situations, with higher scores for those who are more fearful or less confident in these types of situations. Questions measuring fear of uncertainty explicitly mention the 
enjoyment of risky behavior, such as driving fast on a winding road. Shyness focuses on one's willingness to interact with, and level of comfort when around, strangers. Fatigability relates to physical stamina and recovery. People who get tired quickly or do not recover quickly from stress have high fatigability scores (Cloninger et al. (1994)).

People scoring high on reward dependence are generally social and have close relationships with others. The three subscales of reward dependence are sentimentality, attachment, and dependence. Sentimentality looks at how moved one is by emotional stimuli, whether it be direct appeals for help from others or simply a sad movie. Examples include items such as "I am strongly moved by sentimental appeals (like when asked to help crippled children)." and "I feel it is more important to be sympathetic and understanding of other people than to be practical and tough-minded." Attachment measures how much one prefers to be in the company of friends and the openness of one's relationships with friends. Dependence looks at one's desire for others' approval. If a person behaves independent of the wishes of others, he is likely to score low on the subscale dependence (Cloninger et al. (1994)).

Persistence, as the name implies, measures how hard an individual can push herself to achieve her goals. Individuals with high persistence scores work hard despite facing obstacles and lack of recognition of their effort (Cloninger et al. (1994)).

\subsection{Hypotheses based on trait and subscale descriptions}

The trait descriptions lead to the hypotheses that novelty seeking should be positively related to stock market participation and harm avoidance should be negatively related to stock market participation. For individuals with high novelty seeking, the potential rewards of the stock market inspire action. These individuals see the potential for gains from investing and behave accordingly. A person with low novelty seeking will be less likely to respond to the potential rewards of the market and thus he will be less likely to be a stock market participant. Grinblatt and Keloharju (2009) look at stock trading activity as opposed to the general participation question; they show stock trading activity is related to sensation seeking (Zuckerman (1994)), a trait similar to novelty seeking. For individuals high in harm avoidance, the market may be viewed as dangerous. These individuals tend not see the potential reward offered by the market, but instead focus on 
its risks and uncertainty. Persons with high harm avoidance are thus less likely to be stock market participants.

Individuals with high reward dependence are generally more social, having warm relationships with others and seeking out and relying on their approval (Cloninger et al. (1994)). The number and depth of social connections clearly allows for more information sharing, and this information sharing can lower the cost of participation as in Hong et al. (2004). Thus we expect reward dependence to be positively associated with stock market participation. People with high persistence scores remain undeterred when facing challenges (Cloninger et al. (1994)). The link between persistence and stock market participation is likely to be two-channeled: high persistence individuals are more likely to overcome any financial or informational costs associated with investment in the market; and high persistence is also likely to have an effect on one's education or occupation, which in turn affects the participation decision. Thus we expect high persistence people to be more likely to participate in the stock market.

For the novelty seeking subscales, we expect explorative excitability and impulsiveness to be positively related to participation. Individuals with high explorative excitability actively seek new things and get bored easily (Cloninger et al. (1994)). The stock market provides a novel and exciting environment, leading those with high explorative excitability to invest. Impulsive individuals follow their instincts in search of reward, without contemplation and without worrying about having complete information (Cloninger et al. (1994)). Thus we expect persons with high scores on impulsiveness are more likely to be stock market participants. Many of the questions designed to measure extravagance ask about spending money now instead of saving; an individual with a high extravagance score can be interpreted as having a high discount rate and thus be less likely to participate in the stock market. The fourth novelty seeking subscale, disorderliness, reflects the degree to which one dislikes rules or routines (Cloninger et al. (1994)). Does investing in the market break some set of rules or does not investing in the market break some set of rules? There is no clear hypothetical relationship between disorderliness and stock market participation.

We expect the harm avoidance subscales of worry/pessimism and fear of uncertainty to be negatively related to stock market participation. Someone scoring high on worry/pessimism is generally pessimistic about the future and would probably expect poor returns from investing. An easy way to avoid poor returns is to not invest - thus worry/pessimism should be negatively related to stock market participation. Fear of 
uncertainty captures one's fear of unfamiliar and uncertain situations, with higher scores for those who are more fearful or less confident in these types of situations. There is always uncertainty in the market, leading to the hypothesis that high fear of uncertainty leads to lower probability of stock market participation.

The questions measuring the harm avoidance subscale shyness focus on one's willingness to interact with, and level of comfort when around, strangers. We do not interpret shyness as nonsocial. One may be shy around strangers but open with family, friends, and neighbors, so we do not argue for a clear relationship between shyness and participation. The fourth harm avoidance subscale, fatigability, relates to physical stamina and recovery. People who get tired quickly or do not recover quickly from stress have high fatigability scores (Cloninger et al. (1994)). It is difficult to hypothesize a connection between fatigability and market participation.

The reward dependence subscale sentimentality reflects how moved one is by emotional stimuli (Cloninger et al. (1994)). The questions measuring sentimentality range from whether one is moved by appeals for help or sympathy to whether one is likely to cry during a sad movie. The stock market is not an emotional stimulus along these lines; an individual's reaction to market movements depends on long/short investment position in addition to the individual's general level of interest in financial markets. It is thus difficult to form a hypothesis that sentimentality will be positively or negatively related to stock market participation. The reward dependence subscale attachment measures how much one prefers to be in the company of friends and the openness of one's relationships with friends. The subscale dependence looks at one's desire for others' approval (Cloninger et al. (1994)). If a person behaves independent of the wishes of others, he is likely to score low on the subscale dependence. Attachment and dependence can be viewed as measuring how social an individual is. Hong et al. (2004) show the connection between social interaction and stock market participation. Thus we expect a positive relationship between both attachment and dependence and stock market participation.

The traits, subscales, and their hypothesized relationship with stock market participation are displayed in Table 1. Please note that we retain the naming convention of the TCI version IX. Prior to this version, persistence had been a subscale of reward dependence and it had the label "RD2." After being recognized as an independent trait (Cloninger et al. (1993)), persistence adopted its current label "P" and there was no 
relabeling of the remaining reward dependence subscales. Thus, the fact that "RD2" is not present does not reflect a missing subscale.

\section{TABLE 1 ABOUT HERE}

\section{Data And Descriptive Statistics}

We combine Northern Finland Birth Cohort 1966 (NFBC) data with records from Finnish Central Securities Depository (FCSD). The NFBC data contain the personality trait scores and observations on socioeconomic variables. The FCSD data are the official records of individuals' holdings of securities registered in Finland.

\subsection{Northern Finland Birth Cohort 1966}

Started as a project to study maternal and newborn health issues, the cohort data set has expanded over the years to include periodic clinical examinations and postal questionnaires covering heath and socioeconomic issues. Geographically, the cohort members were born in the provinces of Oulu and Lapland. These two provinces make up approximately 50\% of the land area of Finland and had a population of approximately 600,000 in the year 1966 , roughly $14 \%$ of the country's population. ${ }^{6}$ Those with an expected date of birth falling in the period 1 January 1966 - 31 December 1966 were invited to take part in the study. The study chronicled 12231 live and still-born deliveries, of which 6265 were male, 5964 female, and 2 undetermined, which represent over 95\% of all children born in Oulu and Lapland provinces in 1966.

We use information collected when the cohort members were aged 31 in 1997. This 1997 data collection is the first follow up in which the personality questionnaire was used. Information from previous data collections (e.g. at age 16 or earlier) does not offer additional information that would benefit the analysis of the relationship between personality traits and stock market participation. There were 594 individuals who had died by the onset of the 31-year follow-up. Of the 11541 with known addresses, $62 \%$ still lived in northern Finland, 19\% lived in central Finland, 11\% in the Helsinki region, and 7\% outside of Finland. Surveys with questions regarding socioeconomic issues and health issues were sent by mail to all of these individuals. There were 8767 surveys returned, for a response rate of $75.3 \%$. Those living in northern Finland and the Helsinki region were invited to participate in a clinical examination; 6033 (71.3\%)

\footnotetext{
${ }^{6}$ This is based on population of approximately $4.3 \mathrm{~m}$ in 1966 from Statistics Finland website.
} 
participated (see Haapea et al. (2008) for detailed description of the data collection). After deleting from the set those individuals who refused to grant permission to use their data we are left with a core sample that has 3291 individuals. $^{7}$

Socioeconomic and general health questions, along with the temperament portion of the TCI, were included as part of the 31-year old follow-up study. The survey asked cohort members to answer questions regarding marital status, number of children, gross household income, education level, and occupational status. Cohort members also received a survey with true/false questions related to mental health, of which 107 were the temperament questions from TCI (version IX). These 107 questions include 40 novelty seeking questions, 35 harm avoidance questions, 24 reward dependence questions, and 8 persistence questions. For novelty seeking, the number of questions for each subscale is: exploratory excitability 11 ; impulsiveness 10 ; extravagance 9; disorderliness 10. For harm avoidance, the numbers are: worry/pessimism 11; fear of uncertainty 7; shyness 8; fatigability 9. The reward dependence subscales have: sentimentality 10; attachment 8; dependence 6. Answers matching the expected answer for a person exhibiting the trait add one point to the individual's trait score. Questions are worded so that the expected answers are a mix of "true" and "false" responses.

\subsection{Finnish Central Securities Depository}

The FCSD data contain detailed information on the holdings of Finnish investors in securities registered in Finland. Most Finnish publicly traded companies, both exchange-listed and over-the-counter, have their shares and bonds registered in Finland. The data are recorded on a daily basis, with observations for each unique investor-security pair. ${ }^{8}$ Our FCSD data start from January 2, 1995 and continue through December 30, 2010, a total of 4011 trading days. The daily observations include the investor identifier, the purchase day and sale day, if any. From the FCSD data, we identify the investors who are also in the NFBC. ${ }^{9}$ For our main analysis, we define stock market participants as those who held at least one exchange-traded equity security or equity structured product at some point during the years 2003 through 2010 . We do not choose a single date to check for holdings, for example examining stock holdings at year-end 2010. We

\footnotetext{
${ }^{7}$ Written permissions from individuals to use their data were obtained in summer 2012 as part of follow-up NFBC 1966 work.

${ }^{8}$ For more details regarding the FCSD data, see Grinblatt and Keloharju (2000).

${ }^{9}$ This unequivocal identification is possible via a single personal identification number used in Finland. To ensure anonymity the data were matched by Euroclear Finland.
} 
choose to examine the equity holdings over the 2003-2010 window for a few reasons: one, it reduces the possible confounding effect Nokia's dramatic rise and fall may have had on individual's participation decision during the period 1995-2003; two, using only year-end dates to check holdings excludes those individuals who happened to sell all of their equity holdings before the year end, only to buy stocks again the following year - it seems difficult to label these individuals as nonparticipants; and three, the 2003-2010 window gives us more participants (559) than choosing the period 1995-1999 (304 participants), providing for a better test.

There is no doubt that Nokia had a large effect on the Helsinki Stock Exchange and the Finnish economy over the period 1995-2010. In addition to using the long window of 2003-2010 for determining participation, we also exclude any investors who obtained shares in Nokia but did not purchase the shares on the exchange (e.g. shares obtained through employee stock options). While one may expect many people to have been drawn to the stock market because of Nokia, there is no clear evidence for this in our sample. Only 13 individuals chose Nokia for their first share purchase during the period 1995-1999. For the period 2000-2002, only 26 people chose Nokia for their first share purchase. For the period 2003-2010, only 27 individuals did so. Thus 493 investors (88\%) in our sample did not choose Nokia for their first share purchase (individuals who, on their first day of stock market participation, purchased shares of other firms in addition to shares of Nokia are not considered to have purchased Nokia first). Even if we were to eliminate all holdings of Nokia from the database, we would still have 541 stock market participants in the period 2003-2010 (as opposed to the 559 participants in our sample). We cannot rule out that Nokia affected individuals' purchases of other shares through its effect on the Finnish economy. However, there are few individuals who bought shares in Nokia and nothing else. We also eliminate investors whose only holdings are those obtained from a telephone company demutualization.

The data set does not include mutual fund share ownership information. We address this by simply looking at stock market participation in the period 1995-1999. Mutual fund ownership in Finland was still relatively uncommon in 1999; the mutual fund industry in Finland had approximately $10 €$ billion in assets under management in 1999 (Kassanen et al. (2001)). This is a very small number compared to market capitalization of Nokia, which was approximately $200 €$ billion at the end of 1999 . For this early period, we are confident that we are not missing many individuals who participated in the stock market only through 
mutual funds. The effects of the personality traits and subscales on stock market participation are consistent across the two time periods. Because the results are so similar between the two time periods, we put the results for this earlier time period in the appendix.

\subsection{Descriptive Statistics}

We present descriptive statistics in Table 2. For the temperament traits our sample nearly covers the full range of possible scores. The only exceptions are novelty seeking (sample range of 4-39 compared to a possible range of 0-40) and reward dependence (sample range of 2-24 compared to possible range of 0-24). The means of the traits and subscales are generally close to the middle of the range of possible scores. The traits and subscales have nice humped-shaped distributions, although the Jacque-Bera test for normality on the traits and subscales is rejected in every case ${ }^{10}$. Even though the personality trait and subscale scores are not normally distributed, there is enough variation in the traits to allow us to test the relationship between the traits and stock market participation.

\section{TABLE 2 ABOUT HERE}

Our sample is $59 \%$ female. Average household gross income is just over $29000 € .^{11}$ Half of the individuals are married, and $40 \%$ of the individuals live in households with 2 or more children. The educational attainment of our sample is below national averages - our sample has a greater percentage of individuals with only basic education, and a lower percentage with a university degree. The majority of those in our sample are employed as laborers and lower level office workers. Only $9.5 \%$ of the sample reported being unemployed in 1997 , below the national average of $12.7 \%$ at the time. ${ }^{12}$

The stock market participants in our sample seem to be typical of individual investors, as reported in many previous studies: small accounts and lack of diversification. Most of the observations on portfolio value and number of stocks held are for December 30, 2010, but for those who sold all their holdings before this date, we consider the value and number of stocks held on the last day for which the individual held any

\footnotetext{
${ }^{10}$ Jacque-Bera test statistics, p-values, and graphs of the distributions are available upon request.

${ }^{11}$ Income was reported in Finnish Markka on the NFBC survey. We converted to euros using the Markka/Euro exchange rate of 5.95 .

${ }^{12}$ National averages are from Statistics Finland.
} 
shares. The average number of stocks held in the portfolio is only 3.39. The median number of stocks held is 2. The mean account value is $14758 €$, and the median account value is $2905 €$.

Correlation tables are in Appendix A. High correlations between the trait scores and their respective subscales are clearly expected, because the trait score is simply the sum of the subscale scores. The highest correlations for subscale scores within one trait are for harm avoidance, with the correlations between its subscales approaching 0.5 . The cross-trait correlations for subscales are generally within the range of -0.2 and 0.2 .

We acknowledge that our sample is not necessarily representative of the population of Finland. Our sample is, however, well suited to address the personality-stock market participation question. We have a large sample, detailed personality trait scores, controls for other factors known to affect the decision to invest in the stock market, and official register data for equity holdings. The sample offers good variation in personality traits, gender, education, and occupation, allowing us to carefully examine the relationship between the personality traits and stock market participation while controlling for other important investor characteristics.

\section{Results}

\subsection{Differences in Group Means}

We start with a simple analysis of the means of the two groups. Table 3 shows the means for the temperament traits and subscales for stock market participants and nonparticipants. Most of the differences in means are statistically significant. The difference in means between the participants and nonparticipants is not significant for the trait novelty seeking, the subscale impulsiveness, or the subscale dependence. The harm avoidance score and the harm avoidance subscale scores are lower for stock market participants than nonparticipants, as expected. Persistence is higher for stock market participants.

\section{TABLE 3 ABOUT HERE}

The total novelty seeking score is not very different between the groups. Inspection of the novelty seeking subscales reveals the reason: explorative excitability and disorderliness are higher for participants, and extravagance is much lower for participants. Participating in an ever-changing, constant news-flow stock 
market seems ideal for those with higher levels of explorative excitability. Extravagance measures one's preference for spending over saving. The preference for spending over saving can be related to stock market participation in two ways: either higher spending means less money available to invest, or it may imply a higher time discount rate. Distinguishing between these two is difficult but we attempt to answer this question in Table 7. The difference between the reward dependence scores is due to the lower sentimentality scores of participants. Sentimentality in the TCI is related to one's responses to emotional stimuli. People who are "more likely to cry at sad movies" or who are "often moved deeply by a fine speech or poetry" (both examples taken from the TCI questionnaire) have higher sentimentality scores. Determining a specific mechanism by which high sentimentality is negatively related to stock market participation will require further study.

\subsection{Main Regressions}

We perform logistic regressions with a dummy for stock market participation as the dependent variable. For the main results, we define participation as holding equities or equity structured products at any time during the years 2003-2010. ${ }^{13}$ The basic form of the regressions is

$$
\text { Participation }_{i}=\alpha+\beta_{i} T_{C} I_{i}+\gamma_{i} \text { Controls }_{i}+\varepsilon_{i}
$$

Here $T C I_{i}$ refers to the personality trait scores or subscale scores of the individual. As controls, we include gender, log income, dummy variables for level of education, a dummy variable for being married, the number of children, and dummy variables for occupation. All 3291 observations are used in the regressions except when including income, for which we have 3019 observations. The next few paragraphs report the results from Tables 4, 5, and 6. We use standardized TCI scores in the regressions to ease interpretation. We report the regression coefficients and standard errors. The marginal effect reported is the average of the marginal effects calculated for each individual, as in Greene (2008, p. 775).

Table 4 reports the results for regressions that use the trait scores as the main explanatory variables. Model 1 contains only the trait scores (NS, HA, RD, and P). As we define stock market participation as

\footnotetext{
${ }^{13}$ Tables that use the time frame 1955-1999 to measure participation, but otherwise identical to Table 4 and Table 5, are in the appendix.
} 
holding equities any time during 2003-2010 and our controls are from 1997, we add the controls in three steps. Model 2 adds a control for gender. Model 3 has controls for gender and education, the two controls which have limited changes over time. Gender does not change, and educational attainment cannot decrease. Model 4 includes all controls: gender, income, education, marital status, number of children, and occupation.

\section{TABLE 4 ABOUT HERE}

The table shows strong evidence that harm avoidance is negatively related to stock market participation; it remains statistically significant across the three models. The marginal effect of a onestandard-deviation change in harm avoidance is a reduction in the probability of participation by 4 percentage points without controls and 1.7 percentage points when including all controls. The unconditional probability of participation is $17 \%$, so the effects are large. Reward dependence is negatively related to participation and persistence is positively related to participation, but the effects are no longer statistically significant with controls in the regression. Novelty seeking shows a weak negative relationship to stock market participation, but this effect is due entirely to the subscale extravagance, a result shown below in Table 5. The control variables show statistically significant relationships with participation, and all effects are as expected. Females are less likely to participate in the stock market. Income, education and being either a manager or entrepreneur increase the probability of stock market participation. Married people are less likely to participate, and having more children reduces the probability of participation.

Table 5 reports results for regressions using the subscales as the main explanatory variables. As shown in Table 3 above, there is evidence that the total trait scores do not show the relationship between personality and stock market participation as well as the subscales. In Table 5, Model 1 uses only the subscale scores, Model 2 adds gender, Model 3 adds education, and Model 4 includes all controls.

\section{TABLE 5 ABOUT HERE}

For the novelty seeking subscales, we see that extravagance has a large negative effect on participation, with a marginal effect of approximately 4 percentage points. Surprisingly, neither exploratory excitability nor impulsiveness show statistically significant effects on participation. Higher scores on disorderliness are associated with higher likelihood of participation, but his effect drops out when controls are added. The harm avoidance subscales have generally negative coefficients, but only in Model 1 and Model 2 are the coefficients of fear of uncertainty or shyness significant. The reward dependence subscales 
have contrasting effects, with sentimentality having a negative relationship and dependence having a positive relationship with stock market participation. The marginal effect of sentimentality is $4.5 \%$ without controls, and $2 \%$ with controls, while the marginal effect of dependence is $2.5 \%$ without controls and $1 \%$ with controls. Persistence shows some evidence of being positively related to participation, but the effect is not robust to the inclusion of the control variables. The sign, size, and statistical significance of the coefficients on the controls is essentially the same as in Table 4.

We acknowledge three potential problems in the regressions of Tables 4 and 5: firstly, while there is evidence that the temperament traits are relatively stable over adulthood (Joseffson et al., 2013) they may change; secondly, subscales of a trait may be highly correlated, causing estimation problems for regressions that include all the subscales; and thirdly, personality is likely to influence some of the control variables. To address these three issues, we run logistic regressions using only one trait/subscale at a time. We run these regressions for the participation window of 2003-2010 and also for the window 1995-1999. If an individual's scores for the TCI traits changed much over time, the 1997 observation might not reflect well the decision to participate or not during the years 2003-2010. Thus we would likely see differences in the coefficients' magnitude or sign across the two periods. The potential subscale multicollinearity problem is eliminated by using only one subscale at a time. For each time window, we vary the set of controls used: no controls, only gender and education, and all controls.

The results from the trait-by-trait regressions are in Table 6. Novelty seeking shows no relationship with participation, but that is due to the opposing effects of the trait's subscales. Extravagance shows a large negative effect, consistent across model specifications and across the two time periods. Exploratory excitability has a positive effect, but the effect is much stronger in the earlier time period. Individuals who started participating during the later period have, on average, exploratory excitability scores between the nonparticipants and those who owned stocks already in 1995-1999. Impulsiveness shows no relationship with stock market participation. The results for disorderliness are inconclusive; there is weak evidence of a positive relationship in both time periods, but with controls the effect diminishes and even switches sign.

\section{TABLE 6 ABOUT HERE}

Harm avoidance and its subscales have a negative relationship with stock market participation. Across the different specifications, the coefficients are statistically significant with few exceptions. The effects are 
stronger for the early time period, again showing that the "later" participants have harm avoidance scores greater than the "early" participants but lower than the "never" participants. The significance of reward dependence is due entirely to the large negative effect of its subscale sentimentality. Attachment shows essentially no evidence of a relationship with stock market participation, with the coefficients changing size and sign. The coefficients for dependence are consistently positive, but none are statistically significant.

The results in Tables 4-6 support some and reject some of our hypotheses summarized in Table 1. The results that agree with our expectations are the positive relationships of explorative excitability and persistence, with some weak evidence for dependence. The expected positive relationships of novelty seeking, impulsiveness, reward dependence, and attachment are not supported in the data. We find evidence supporting our expectations for the negative effects of extravagance, harm avoidance, worry/pessimism, and fear of uncertainty. For the traits that we could not form clear expected relationships, we found: a strong negative effect for sentimentality; weak positive effect of disorderliness; and negative effects for shyness and fatigability.

The fact that two subscales have opposite signs does not present a problem. The psychobiological basis for the personality traits supports the descriptions of the traits and their respective subscales. From the perspective of psychiatry, explorative excitability and extravagance exemplify similar behavioral responses to stimuli (that of behavioral activation) which conceivably have roots in the same underlying structure in the brain (Cloninger (1987) and Cloninger et al. (1993)). From an economic perspective, the excitement of the stock market encourages those high in explorative excitability to participate, while the high discount rate of extravagant individuals discourages participation.

\subsection{Additional Tests}

\subsubsection{High Socioeconomic Status}

Thus far we have shown that the TCI traits and subscales affect stock market participation, even when controlling for gender, education, occupation, and income. However, we can take an additional step to examine the effect of personality on stock market participation. Gender is known to affect personality (see Miettunen et al. (2004) for an example of the difference in personality traits between genders in NFBC1966) and it is likely that personality is related to the outcomes of the other control variables. The results in Tables 
4 and 5 show that education and occupation have large effects on stock market participation. If the effect of personality on stock market participation occurs mainly through personality's effect on education and occupation, then looking at a subsample of only those individuals with both a university degree and a managerial level occupation should eliminate some or all of the effect of the traits on participation. The logistic regression results are presented in Table 7 for this subsample of high socioeconomic status individuals, showing the results for both the 1995-1999 and 2003-2010 participation windows. We see that exploratory excitability, extravagance, sentimentality, and dependence all have large and statistically significant coefficients. In this subsample, gender is a weak predictor of stock market participation, and only for the later time period. Exploratory excitability and dependence increase participation and extravagance and sentimentality decrease participation. The effects are large. For these four subscales, one-standarddeviation changes in the scores change the probability of stock market participation in the range of 5 to 12 percentage points.

\section{TABLE 7 ABOUT HERE}

The large coefficient for dependence in this subsample supports the result in Table 5 but contrasts the results in Table 6. In Table 5, we saw that dependence was positively related to stock market participation, although the effect was diminished as controls were added. In the trait-by-trait analysis in Table 6 there was no statistically significant effect. In Table 7, the effect of dependence is large. We interpret this as evidence for dependence being a good proxy for sociability. Hong et al. (2004) show the effect of sociability on stock market participation is stronger in areas where there are more stock market participants - socializing with other participants increases the likelihood of participating. Individuals with high socioeconomic status are more likely to participate in the stock market; as Table 7 shows, those with higher scores for dependence (the more social members of this group) are also more likely to be stock market participants.

The subsample used in Table 7 also helps us to conclude that the effect of extravagance is related to time-discounting and not to having investable funds available after consumption spending. The variation in income is smaller for this subsample compared to the sample used in Tables 5 and 6 , and we still control for income in Table 7. For this subsample, individuals are less likely to face constraints on their funds available for investment. If the effect of extravagance on stock market participation demonstrated in Tables 5 and 6 were solely related to having investable funds available after consumption, the effect of extravagance should 
not be significant in Table 7. The fact that extravagance is still statistically significant in the high socioeconomic subsample indicates that extravagance is more related to time discounting than to having funds available for investment after consumption.

\subsubsection{Exiting the Stock Market}

Since personality traits represent repeated patterns of behavior, the traits may also affect the behavior of those who have chosen to participate in the market. Conditional on being a stock market participant, does personality affect exiting the market? Table 8 shows the results from the logistic regression of stock market exit on the personality subscales and controls. We define exit as permanently selling all equity holdings any time before 31 December 2010. Of the 559 individuals participating in 2003-2010, 121 of them permanently exit the market. For exploratory excitability, extravagance, and sentimentality, we find statistically significant effects on exiting the market. Lower exploratory excitability, higher extravagance and higher sentimentality increase the likelihood of exit. We know from Tables 5, 6, and 7 that lower exploratory excitability, higher extravagance and higher sentimentality all reduce the likelihood of participating in the stock market. Increasing the probability of exiting the market is analogous to decreasing the probability of entering the market; both indicate greater likelihood of being out of the market.

\section{TABLE 8 ABOUT HERE}

Disorderliness shows evidence of a positive association with exiting the market, albeit statistically significant only at the $10 \%$ level. Higher disorderliness is thus positively associated with both stock market entry and exit. We saw in Table 3 that the mean disorderliness score for participants was higher than nonparticipants (4.25 vs 4.09). The 121 participants that eventually exit the market have a mean score 4.58. Disorderliness thus seems to capture a willingness to go against the standard investment advice of buy and hold for the long term.

\section{Conclusion}

This study creates a unique data set by combining personality trait measurements from the Northern Finland Birth Cohort 1966 with stock holdings information from the Finnish Central Securities Depository registry. We use temperament trait and subscale scores from Cloninger et al.'s (1993) Temperament and Character Inventory. Some of the trait scores and subscales scores are significant indicators of stock market 
participation. We find that the subscale scores provide more information than the total trait scores. The novelty seeking subscale exploratory excitability has an offsetting effect relative to extravagance, as do the reward dependence subscales of sentimentality and dependence. We show that exploratory excitability, extravagance, harm avoidance (and its subscales), sentimentality and persistence are consistently related to stock market participation across time periods and varying model specifications.

The description of fear of uncertainty, a harm avoidance subscale, allows us to use it as a proxy for risk aversion. We show that fear of uncertainty is negatively related to stock market participation, albeit weakly. Also, by controlling for risk aversion in our analysis, we show that the other personality traits are robust to its inclusion. We do not have observations on individuals' wealth, but we do have observations for income, education, and occupation, which can proxy for wealth. Thus we show that personality traits' relationship with stock market participation is robust to the inclusion of both risk aversion and wealth.

The results of the study support previous research on stock market participation and add to the growing literature of using personality to predict economic behavior. The relationship between exploratory excitability and participation adds to the literature using sensation seeking as a predictor of economic behavior. The relationship between dependence and participation builds on the studies showing investing behavior being influenced by social interaction. The interpretation of sentimentality's negative relationship with participation is currently unclear, and more work is necessary. The strong negative relationship between extravagance and participation, even amongst high socioeconomic status individuals, provides evidence that extravagance may be a good proxy for time preferences.

The paper shows the benefit of using personality data when looking at the participation decision. Personality traits have been useful in researching other economic phenomenon. Through continued research in both psychology and economics, the effects of personality on economic decision making should become clearer. As for policy, the effect of personality traits is difficult to determine. Personality may make targeting policy more difficult because individuals who are in the same socioeconomic target group but have differing personality traits may respond differently. Consider a proposed reduction in the capital gains tax meant to increase long-term investment; it increases allocation to stocks for some, but those with high extravagance 
are not persuaded to invest. While personality is one of many factors affecting decision making, the strength of the traits' relationship with certain outcomes shows the potential personality traits have in finance and economics research. 


\section{References}

Almlund, M., Duckworth, A. L., Heckman, J. J., \& Kautz, T. D., 2011. Personality psychology and economics. NBER Working Papers (16822).

Ameriks, J., Wranik, T., Salovey, P., 2009 Emotional intelligence and investor behavior. Res. Found. Publications 1-75.

Barber, B. M., \& Odean, T. 2001. Boys will be boys: Gender, overconfidence, and common stock investment. Q. J. Econ. 116(1), 261-292.

Borghans, L., Duckworth, A. L., Heckman, J. J., \& Ter Weel, B., 2008. The economics and psychology of personality traits. J. Hum. Resour., 43(4), 972-1059.

Brown, S., and Taylor, K., 2011. Household finances and the 'big five' personality traits. IZA Discussion Paper No. 6191.

Christelis, D., Jappelli, T., \& Padula, M., 2010. Cognitive abilities and portfolio choice. Eur. Econ. Rev. 54(1), 18-38.

Cloninger, C. R., 1987. A Systematic method for clinical description and classification of personality variants: a proposal. Arch. Gen. Psychiatry. 44, 573-588.

Cloninger, C.R., Przybeck, T.R., Svrakic, D.M., and Wetzel, R.D., 1994. The Temperament and Character Inventory (TCI): a guide to its development and use. St. Louis: Washington University, Center for Psychobiology of Personality.

Cloninger, C. R., Sigvardsson, S., \& Bohman, M., 1988. Childhood personality predicts alcohol abuse in young adults. Alcohol.: Clin. Exp. Res., 12(4), 494-505.

Cloninger, C. R., Svrakic, D. M., and Przybeck, T. R., 1993. A Psychobiological model of temperament and character. Arch. Gen. Psychiat. 50.12, 975-990.

Cole, S. A., and Shastry, G. K., 2009. Smart money: the effect of education, cognitive ability, and financial literacy on financial market participation. Harvard Business School Working Paper.

De Fruyt, F., Van De Wiele, L., \& Van Heeringen, C., 2000. Cloninger's psychobiological model of temperament and character and the five-factor model of personality. Pers. Indiv. Differ. 29(3), 441-452.

Dimmock, S. G., \& Kouwenberg, R., 2010. Loss-aversion and household portfolio choice. J. Empir. Financ. 17(3), 441-459.

Dohmen, T., Falk, A., Huffman, D., Sunde, U., Schupp, J., and Wagner, G.G., 2011. Individual risk attitudes: measurement, determinants and behavioral consequences. J. Eur. Econ. Assoc. 9.3, 522-550.

Ebstein, R. P., Novick, O., Umansky, R., Priel, B., Osher, Y., Blaine, D., Bennett, E.R., Nemanov, L., Katz, M., and Belmaker, R. H., 1996. Dopamine D4 receptor (D4DR) exon III polymorphism associated with the human personality trait of novelty seeking. Nat. Genet., 12(1), 78-80.

Ekelund, J., Johansson, E., Järvelin, M. R., \& Lichtermann, D., 2005. Self-employment and risk aversionevidence from psychological test data. Labour Econ. 12(5), 649-659. 
Gerra, G., Zaimovic, A., Timpano, M., Zambelli, U., Delsignore, R., \& Brambilla, F., 2000. Neuroendocrine correlates of temperamental traits in humans. Psychoneuroendocrinology, 25(5), 479-496.

Gosling, S. D., Rentfrow, P. J., \& Swann, W. B., 2003. A very brief measure of the Big-Five personality domains. J. Res. Pers., 37(6), 504-528.

Greene, W.H., 2008. Econometric Analysis. Prentice Hall.

Grinblatt, M. and Keloharju, M., 2000. The Investment behavior and performance of various investor types: a study of Finland's unique data set. J. Financ. Econ. 55, 43-67.

Grinblatt, M., and Keloharju, M., 2009. Sensation Seeking, Overconfidence, and Trading Activity. J. Financ. 64.2, 549-578.

Grinblatt, M., Keloharju, M., and Linnainmaa, J., 2011. IQ and stock market participation. J. Financ. 66.6, 2121-2164.

Guiso, L., and Jappelli, T., 2005. Awareness and stock market participation. Rev. Financ. 9.4, 537-567.

Guiso, L., Sapienza, P., and Zingales, L., 2008. Trusting the stock market. J. Financ. 63.6, 2557-2600.

Haapea, M., Miettunen, J., Läärä, E., Joukamaa, M.I., Järvelin, M-R., Isohanni, M.K., and Veijola, J.M., 2008. Non-participation in a field survey respect to psychiatric disorders. Scand. J. Public Healt. 36, 728-736.

Halko, M-L., Kaustia, M., and Alanko, E., 2012. The Gender effect in risky asset holdings. J. Econ. Behav. Organ. 83.1, 66-81.

Hong, H., Kubik, J. D., and Stein, J. C., 2004. Social interaction and stock market participation. J. Financ. 59.1, 137-163.

Josefsson, K., Jokela, M., Cloninger, C. R., Hintsanen, M., Salo, J., Hintsa, T., Pulkki-Råback, L., and Keltikangas-Järvinen, L., 2013. Maturity and change in personality: developmental trends of temperament and character in adulthood. Dev. Psychopathol., 25(03), 713-727.

Kahneman, D., \& Tversky, A., 1979. Prospect theory: an analysis of decision under risk. Econometrica 47.2, 263-291.

Kamstra, M. J., Kramer, L. A., \& Levi, M. D. 2003. Winter blues: a SAD stock market cycle. Am. Econ. Rev. 93.1, 324-343.

Kasanen, E., Lipponen, V., and Puttonen, V., 2001. What determines mutual fund growth: evidence from Finland. Liiketaloudellinen Aikakauskirja, 227-259.

Kaustia, M., and Knüpfer, S., 2012. Peer performance and stock market entry. J. Financ. Econ. 104.2, 321338.

Kaustia, M., and Torstila, S., 2011. Stock market aversion? Political preferences and stock market participation. J. Financ. Econ. 100.1, 98-112.

Kühn, K.-U., Meyer, K., Nöthen, M. M., Gänsicke, M., Papassotiropoulos, A. and Maier, W., 1999. Allelic variants of dopamine receptor D4 (DRD4) and serotonin receptor 5HT2c (HTR2c) and temperament factors: Replication tests. Am. J. Med. Genet., 88: 168-172. 
Markon, K. E., Krueger, R. F., \& Watson, D., 2005. Delineating the structure of normal and abnormal personality: an integrative hierarchical approach. J. Pers. Soc. Psychol., 88(1), 139.

Martinotti, G., Andreoli, S., Giametta, E., Poli, V., Bria, P., and Janiri, L., 2006. The dimensional assessment of personality in pathologic and social gamblers: the role of novelty seeking and self-transcendence. Compr. Psychiatry, 47(5), 350-356.

McCrae, R., and Costa Jr., P., 1997. Personality trait structure as a human universal. Am. Psychol. 52(5), $509-516$.

Melke, J., Westberg, L., Nilsson, S., Landén, M., Soderstrom, H., Baghaei, F., Rosmond, R., Holm, G., Björntorp, P., Nilsson, L-G., Adolfsson, R., Eriksson, E., 2003. A polymorphism in the serotonin receptor 3A (HTR3A) gene and its association with harm avoidance in women. Arch. Gen. Psychiatry, 60(10):1017-1023.

Miettunen, J., Kantojärvi, L., Ekelund, J., Veijola, J., Karvonen, J.T., Peltonen, L., Järvelin, M-R., Freimer, N., Lichtermann, D., Joukamaa, M., 2004. A large population cohort provides normative data for investigation of temperament. Acta Psychiat. Scand. 110, 150-157.

Milivojevic, D., Milovanovic, S. D., Jovanovic, M., Svrakic, D. M., Svrakic, N. M., Svrakic, S. M. and Cloninger, C. R., 2012. Temperament and character modify risk of drug addiction and influence choice of drugs. Am. J. Addict., 21: 462-467.

Mischel, W., Shoda, Y., \& Rodriguez, M. I., 1989. Delay of gratification in children. Sci., 244(4907), 933938.

Peirson, A. R., Heuchert, J. W., Thomala, L., Berk, M., Plein, H., and Cloninger, C. R., 1999. Relationship between serotonin and the temperament and character inventory. Psychiatry research, 89(1), 29-37.

Roberts, B. W., 2009. Back to the future: Personality and Assessment and personality development. J. Res. Pers. 43(2), 137-145.

Service, S.K., Verweij, K., Lahti, J., Congdon, E., Ekelund, J., Hintsanen, M., Räikkönen, K., Lehtimäki, T., Kähönen, M., Widen, E., Taanila, A., Veijola, J., Heath, A.C., Madden, P.A.F., Montgomery, G.W., Sabatti, C., Järvelin, M-R., Palotie, A., Raitakari, O., Viikari, J., Martin, N.G., Eriksson, J.G., Keltikangas-Järvinen, L., Wray, N.R., Freimer, N.B., 2012. A genome-wide meta-analysis of association studies of Cloninger's Temperament Scales. Translational Psychiat., 2(5), e116.

Statistics Finland, Population statistics, http://www.stat.fi/tup/suoluk/suoluk_vaesto_en.html.

Van Rooij, M., Lusardi, A., \& Alessie, R., 2011. Financial literacy and stock market participation. J. Financ. Econ. 101(2), 449-472.

Vissing-Jørgensen, A., 2003. Perspectives on behavioral finance: does" irrationality" disappear with wealth? Evidence from expectations and actions. in Gertler, M., and Rogoff, K., (Eds.). NBER Macroeconomics Annual 2003. MIT Press, Cambridge, MA.

Wills, T. A., Vaccaro, D., and McNamara, G., 1994. Novelty seeking, risk taking, and related constructs as predictors of adolescent substance use: an application of Cloninger's theory. J. Subst. ance Abus., 6(1), 1-20. 
Zuckerman, M., 1994. Behavioral expressions and biosocial bases of sensation seeking. Cambridge University Press. 
Table 1 Expected Relationship between Personality Traits and Stock Market Participation

The table shows the expected relationship with stock market participation for both the traits (no numerical index) and the subscales (with numerical index).

\begin{tabular}{lll}
\hline Positive & Negative & Indeterminate \\
\hline $\begin{array}{l}\text { Novelty Seeking (NS) } \\
\text { Explorative }\end{array}$ & Harm Avoidance (HA) & Disorderliness (NS4) \\
excitability(NS1) & Extravagance (NS3) & Shyness (HA3) \\
Impulsiveness (NS2) & Worry/pessimism (HA1) & Fatigability (HA4) \\
Reward Dependence (RD) & Fear of uncertainty (HA2) & Sentimentality (RD1) \\
Attachment (RD3) & & \\
$\begin{array}{l}\text { Dependence (RD4) } \\
\text { Persistence (P) }\end{array}$ & \\
\hline
\end{tabular}




\section{Table 2 Summary Statistics}

The table shows summary statistics for the TCI temperament scores and socioeconomic variables from the NFBC survey in 1997, and investor portfolios from the FCSD. The survey results cover the full range of possible temperament scores, except for novelty seeking (0-40) and reward dependence (0-24). Income is in euros, converted from values reported in Finnish markka. Education variables are dummy variables representing the highest level of education achieved. Occupation variables are dummy variables. "Other Employment Status" includes the unemployed, students, retired, and those on disability. Participation is a dummy for those who held an exchange-traded stock or equity structured product at any point during the period 2003 - 2010. Number of stocks and portfolio value (in euros) are for the last available observation in $2003-2010$.

\begin{tabular}{lrrrrrr}
\hline Variable & $\mathrm{N}$ & Mean & Median & Std Dev & Min & Max \\
\hline Novelty Seeking (NS) & 3291 & 20.37 & 20 & 5.87 & 4 & 39 \\
Explorative excitability(NS1) & 3291 & 6.69 & 7 & 2.31 & 0 & 11 \\
Impulsiveness (NS2) & 3291 & 4.33 & 4 & 2.43 & 0 & 10 \\
Extravagance (NS3) & 3291 & 5.23 & 6 & 2.24 & 0 & 9 \\
Disorderliness (NS4) & 3291 & 4.12 & 4 & 1.81 & 0 & 10 \\
Harm Avoidance (HA) & 3291 & 13.94 & 14 & 6.09 & 0 & 35 \\
$\quad$ Worry/pessimism (HA1) & 3291 & 3.68 & 3 & 2.08 & 0 & 11 \\
Fear of uncertainty (HA2) & 3291 & 3.80 & 4 & 1.82 & 0 & 7 \\
$\quad$ Shyness (HA3) & 3291 & 3.68 & 4 & 2.11 & 0 & 8 \\
$\quad$ Fatigability (HA4) & 3291 & 2.78 & 3 & 1.84 & 0 & 9 \\
Reward Dependence (RD) & 3291 & 14.83 & 15 & 3.79 & 2 & 24 \\
$\quad$ Sentimentality (RD1) & 3291 & 5.39 & 5 & 2.12 & 0 & 10 \\
$\quad$ Attachment (RD3) & 3291 & 5.63 & 6 & 2.09 & 0 & 8 \\
$\quad$ Dependence (RD4) & 3291 & 3.81 & 4 & 1.41 & 0 & 6 \\
Persistence (P) & 3291 & 4.28 & 4 & 1.73 & 0 & 8 \\
Female & & & & & & \\
Income $€$ & 3291 & 0.59 & 1 & 0.49 & 0 & 1 \\
Married & 3021 & 29219 & 28592 & 18447 & 0 & 672752 \\
Number of Children & 3291 & 0.51 & 1 & 0.50 & 0 & 1 \\
Basic Education & 3291 & 1.28 & 1 & 1.29 & 0 & 9 \\
Secondary Education & 3291 & 0.54 & 1 & 0.50 & 0 & 1 \\
University & 3291 & 0.32 & 0 & 0.47 & 0 & 1 \\
Worker & 3291 & 0.13 & 0 & 0.33 & 0 & 1 \\
Manager & 3291 & 0.58 & 1 & 0.49 & 0 & 1 \\
Entrepreneur & 3291 & 0.19 & 0 & 0.39 & 0 & 1 \\
Other Employment Status & 3291 & 0.06 & 0 & 0.24 & 0 & 1 \\
Participation & 3291 & 0.18 & 0 & 0.38 & 0 & 1 \\
Number of Stocks & & & & & & \\
Portfolio value $€$ & 5291 & 0.17 & 0 & 0.38 & 0 & 1 \\
\hline & 559 & 14758 & 2905 & 37479 & 0 & 371096 \\
\hline
\end{tabular}




\section{Table 3 Means of Personality Trait Scores by Participation}

The table shows the means and means test of the personality traits and subscales for stock market participants and nonparticipants. Variances of the samples are assumed to be equal. *,**, and *** denote significance at the $10 \%, 5 \%$, and $1 \%$ level, respectively.

\begin{tabular}{|c|c|c|c|}
\hline Temperament traits and subscales & Nonparticipants & Participants & t-value \\
\hline Novelty Seeking (NS) & 20.43 & 20.04 & -1.45 \\
\hline Explorative excitability(NS1) & 6.65 & 6.85 & $1.83 * *$ \\
\hline Impulsiveness (NS2) & 4.34 & 4.29 & -0.44 \\
\hline Extravagance (NS3) & 5.35 & 4.65 & $-6.72 * * *$ \\
\hline Disorderliness (NS4) & 4.09 & 4.25 & $1.79 * *$ \\
\hline Harm Avoidance (HA) & 14.24 & 12.43 & $-6.46^{* * * *}$ \\
\hline Worry/pessimism (HA1) & 3.75 & 3.34 & $-4.20 * * *$ \\
\hline Fear of uncertainty (HA2) & 3.89 & 3.35 & $-6.35^{* * *}$ \\
\hline Shyness (HA3) & 3.76 & 3.29 & $-4.81 * * *$ \\
\hline Fatigability (HA4) & 2.85 & 2.45 & $-4.77 * * *$ \\
\hline Reward Dependence (RD) & 15.00 & 14.02 & $-5.57 * * *$ \\
\hline Sentimentality (RD1) & 5.52 & 4.73 & $-8.13 * * *$ \\
\hline Attachment (RD3) & 5.68 & 5.41 & $-2.76^{* * * *}$ \\
\hline Dependence (RD4) & 3.80 & 3.88 & 1.26 \\
\hline Persistence (P) & 4.21 & 4.64 & $5.36^{* * *}$ \\
\hline
\end{tabular}




\section{Table 4 Personality Traits and Stock Market Participation 2003-2010}

The dependent variable in these logistic regressions is 1 for those who were stock market participants in the period 2003-2010. The TCI temperament scores and socioeconomic variables are from the NFBC survey in 1997. The TCI scores are standardized to mean zero and standard deviation of 1 . Income is in euros. Children is the number of children in the household. Education variables are dummy variables representing the highest level of education achieved; the omitted class is basic education. Occupations are dummy variables; the omitted classes are workers and others. Panel A reports the coefficients and standard errors. $\mathrm{c}$ is the area under the receiver operator characteristic (ROC) curve. *,**, and $* * *$ denote significance at the $10 \%, 5 \%$, and $1 \%$ levels, respectively. Panel B reports the average of the marginal effects calculated for each observation.

Panel A: Coefficients and Standard Errors

\begin{tabular}{|c|c|c|c|c|c|c|c|c|}
\hline & \multicolumn{2}{|l|}{ Model 1} & \multicolumn{2}{|l|}{ Model 2} & \multicolumn{2}{|l|}{ Model 3} & \multicolumn{2}{|l|}{ Model 4} \\
\hline & Coef. & S.E. & Coef. & S.E. & Coef. & S.E. & Coef. & S.E. \\
\hline Novelty Seeking NS & $-0.094 * *$ & 0.050 & -0.047 & 0.051 & -0.057 & 0.053 & $-0.106^{*}$ & 0.055 \\
\hline Harm Avoidance HA & $-0.290 * * *$ & 0.053 & $-0.208 * * *$ & 0.054 & $-0.158 * * *$ & 0.056 & $-0.135^{* *}$ & 0.059 \\
\hline Reward Dependence RD & $-0.241 * * *$ & 0.047 & $-0.098 *$ & 0.051 & $-0.101 *$ & 0.053 & -0.068 & 0.056 \\
\hline Persistence P & $0.160 * * *$ & 0.050 & $0.140 * * *$ & 0.050 & $0.097 *$ & 0.052 & 0.034 & 0.054 \\
\hline Female & & & $-0.830 * * *$ & 0.106 & $-1.038 * * *$ & 0.112 & $-0.939 * * *$ & 0.119 \\
\hline Ln(Income) & & & & & & & $0.445 * * *$ & 0.101 \\
\hline Secondary Ed. & & & & & $0.812 * * *$ & 0.115 & $0.637 * * *$ & 0.125 \\
\hline University Ed. & & & & & $1.470 * * *$ & 0.133 & $0.913 * * *$ & 0.171 \\
\hline Married & & & & & & & $-0.370 * * *$ & 0.126 \\
\hline Children & & & & & & & $-0.181 * * *$ & 0.054 \\
\hline Manager & & & & & & & $0.640 * * *$ & 0.141 \\
\hline Entrepreneur & & & & & & & $0.676 * * *$ & 0.19 \\
\hline Constant & $-1.650 * * *$ & 0.049 & $-1.209 * * *$ & 0.071 & $-1.622 * * *$ & 0.086 & $-6.637 * * *$ & 1.186 \\
\hline c & 0.63 & & 0.66 & & 0.75 & & 0.74 & \\
\hline Pseudo-R2 & 0.05 & & 0.08 & & 0.16 & & 0.18 & \\
\hline $\mathrm{N}$ & 3291 & & 3291 & & 3291 & & 3019 & \\
\hline
\end{tabular}

Panel B: Marginal Effects

\begin{tabular}{lllll}
\hline & Model 1 & Model 2 & Model 3 & Model 4 \\
\hline Novelty Seeking NS & -0.013 & -0.006 & -0.007 & -0.014 \\
Harm Avoidance HA & -0.040 & -0.028 & -0.020 & -0.017 \\
Reward Dependence RD & -0.033 & -0.013 & -0.013 & -0.009 \\
Persistence P & 0.022 & 0.019 & 0.012 & 0.004 \\
\hline Unconditional & 0.170 & 0.170 & 0.170 & 0.177 \\
\hline
\end{tabular}




\section{Table 5 Personality Subscales and Stock Market Participation 2003-2010}

The dependent variable in these logistic regressions is 1 for those who were stock market participants in the period 2003-2010. The TCI temperament subscale scores and socioeconomic variables are from the NFBC survey in 1997. The TCI subscale scores are standardized to mean zero and standard deviation of 1 . Income is in euros. Children is the number of children in the household. Education variables are dummy variables representing the highest level of education achieved; the omitted class is basic education. Occupations are dummy variables; the omitted classes are workers and others. Panel A reports the coefficients and standard errors. $\mathrm{c}$ is the area under the receiver operator characteristic (ROC) curve. *,**, and *** denote significance at the 10\%, 5\%, and 1\% levels, respectively. Panel B reports the average of the marginal effects calculated for each observation. 
Table 5

Panel A: Coefficients and Standard Errors

\begin{tabular}{|c|c|c|c|c|c|c|c|c|}
\hline & Model 1 & & Model 2 & & Model 3 & & Model 4 & \\
\hline & Coef. & S.E. & Coef. & S.E. & Coef. & S.E. & Coef. & S.E. \\
\hline $\begin{array}{l}\text { Exploratory } \\
\text { excitability(NS1) }\end{array}$ & 0.065 & 0.060 & 0.088 & 0.061 & 0.078 & 0.062 & 0.066 & 0.066 \\
\hline Impulsiveness (NS2) & 0.057 & 0.055 & 0.089 & 0.055 & $0.097 *$ & 0.056 & 0.088 & 0.058 \\
\hline Extravagance (NS3) & $-0.338 * * *$ & 0.053 & $-0.312 * * *$ & 0.054 & $-0.305^{* * *}$ & 0.055 & $-0.310 * * *$ & 0.058 \\
\hline Disorderliness (NS4) & $0.128 * *$ & 0.052 & $0.107 *$ & 0.053 & 0.062 & 0.054 & -0.005 & 0.057 \\
\hline Worry/pessimism (HA1) & -0.04 & 0.061 & -0.024 & 0.062 & 0.013 & 0.063 & 0.058 & 0.066 \\
\hline Fear of uncertainty (HA2) & $-0.106^{*}$ & 0.062 & -0.022 & 0.064 & -0.058 & 0.066 & -0.052 & 0.069 \\
\hline Shyness (HA3) & $-0.141 * *$ & 0.063 & $-0.166 * * *$ & 0.064 & -0.102 & 0.066 & -0.096 & 0.068 \\
\hline Fatigability (HA4) & -0.008 & 0.064 & -0.005 & 0.064 & -0.03 & 0.066 & -0.055 & 0.070 \\
\hline Sentimentality (RD1) & $-0.341 * * *$ & 0.052 & $-0.226 * * *$ & 0.056 & $-0.172 * * *$ & 0.057 & $-0.152 * *$ & 0.060 \\
\hline Attachment (RD3) & $-0.100^{*}$ & 0.055 & -0.057 & 0.056 & -0.052 & 0.057 & -0.007 & 0.060 \\
\hline Dependence (RD4) & $0.188 * * *$ & 0.051 & $0.165 * * *$ & 0.051 & $0.116^{* *}$ & 0.053 & 0.085 & 0.055 \\
\hline Persistence (P) & $0.205 * * *$ & 0.055 & $0.176^{* * *}$ & 0.056 & $0.109^{*}$ & 0.057 & 0.029 & 0.060 \\
\hline Female & & & $-0.682 * * *$ & 0.113 & $-0.914 * * *$ & 0.120 & $-0.833 * * *$ & 0.126 \\
\hline Ln(Income) & & & & & & & $0.414 * * *$ & 0.102 \\
\hline Secondary Ed. & & & & & $0.767 * * *$ & 0.117 & $0.598 * * *$ & 0.127 \\
\hline University Ed. & & & & & $1.393 * * *$ & 0.135 & $0.858 * * *$ & 0.174 \\
\hline Married & & & & & & & $-0.390 * * *$ & 0.127 \\
\hline Children & & & & & & & $-0.190 * * *$ & 0.055 \\
\hline Manager & & & & & & & $0.634 * * *$ & 0.144 \\
\hline Entrepreneur & & & & & & & $0.654 * * *$ & 0.192 \\
\hline Constant & $-1.716^{* * *}$ & 0.052 & $-1.343 * * *$ & 0.077 & $-1.709 * * *$ & 0.09 & $-6.323 * * *$ & 1.193 \\
\hline $\mathrm{c}$ & 0.68 & & 0.70 & & 0.73 & & 0.75 & \\
\hline Pseudo-R2 & 0.09 & & 0.11 & & 0.16 & & 0.2 & \\
\hline $\mathrm{N}$ & 3291 & & 3291 & & 3291 & & 3019 & \\
\hline \multicolumn{9}{|l|}{ Panel B: Marginal Effects } \\
\hline & Model 1 & & Model 2 & & Model 3 & & Model 4 & \\
\hline $\begin{array}{l}\text { Exploratory } \\
\text { excitability(NS1) }\end{array}$ & 0.009 & & 0.012 & & 0.010 & & 0.008 & \\
\hline Impulsiveness (NS2) & 0.008 & & 0.012 & & 0.012 & & 0.011 & \\
\hline Extravagance (NS3) & -0.045 & & -0.041 & & -0.038 & & -0.039 & \\
\hline Disorderliness (NS4) & 0.017 & & 0.014 & & 0.008 & & -0.001 & \\
\hline Worry/pessimism (HA1) & -0.005 & & -0.003 & & 0.002 & & 0.007 & \\
\hline Fear of uncertainty (HA2) & -0.014 & & -0.003 & & -0.007 & & -0.006 & \\
\hline Shyness (HA3) & -0.019 & & -0.022 & & -0.013 & & -0.012 & \\
\hline Fatigability (HA4) & -0.001 & & -0.001 & & -0.004 & & -0.007 & \\
\hline Sentimentality (RD1) & -0.045 & & -0.030 & & -0.022 & & -0.019 & \\
\hline Attachment (RD3) & -0.013 & & -0.007 & & -0.007 & & -0.001 & \\
\hline Dependence (RD4) & 0.025 & & 0.022 & & 0.015 & & 0.011 & \\
\hline Persistence $(\mathrm{P})$ & 0.027 & & 0.023 & & 0.014 & & 0.004 & \\
\hline Unconditional Probability & 0.170 & & 0.170 & & 0.170 & & 0.177 & \\
\hline
\end{tabular}




\section{Table 6 Personality and Stock Market Participation, Trait-by-Trait Analysis}

The dependent variable is these logistic regressions is 1 for stock market participants in the given time period. The TCI scores are standardized to mean zero and standard deviation of 1 . We ran separate regressions for each trait and subscale, while varying the controls. Columns 1 and 4 have no other controls. Columns 2 and 5 have controls for gender and education. Columns 3 and 6 further add controls for income, occupation, and family status. Columns 1,2,4, and 5 have 3291 observations, while columns 3 and 6 have 3019 observations. Standard errors are in parentheses below the coefficients. $* * *$, and $* * *$ denote significance at the $10 \%, 5 \%$, and $1 \%$ levels, respectively.

\begin{tabular}{|c|c|c|c|c|c|c|}
\hline \multirow[b]{2}{*}{ Novelty Seeking (NS) } & \multicolumn{3}{|c|}{ 1995-1999 } & \multicolumn{3}{|c|}{ 2003-2010 } \\
\hline & $\begin{array}{l}0.006 \\
(0.060)\end{array}$ & $\begin{array}{l}0.033 \\
(0.062)\end{array}$ & $\begin{array}{l}-0.032 \\
(0.065)\end{array}$ & $\begin{array}{l}-0.068 \\
(0.047)\end{array}$ & $\begin{array}{l}-0.029 \\
(0.049)\end{array}$ & $\begin{array}{l}-0.078 \\
(0.051)\end{array}$ \\
\hline Exploratory excitability(NS1) & $\begin{array}{l}0.219 * * * \\
(0.064)\end{array}$ & $\begin{array}{l}0.210 * * * \\
(0.067)\end{array}$ & $\begin{array}{l}0.163 * * \\
(0.069)\end{array}$ & $\begin{array}{l}0.086 * \\
(0.047)\end{array}$ & $\begin{array}{l}0.088 * \\
(0.050)\end{array}$ & $\begin{array}{l}0.051 \\
(0.053)\end{array}$ \\
\hline Impulsiveness (NS2) & $\begin{array}{l}0.051 \\
(0.060)\end{array}$ & $\begin{array}{l}0.110 * \\
(0.062)\end{array}$ & $\begin{array}{l}0.078 \\
(0.064)\end{array}$ & $\begin{array}{l}-0.021 \\
(0.047)\end{array}$ & $\begin{array}{l}0.040 \\
(0.048)\end{array}$ & $\begin{array}{l}0.014 \\
(0.050)\end{array}$ \\
\hline Extravagance (NS3) & $\begin{array}{l}-0.341^{* * * *} \\
(0.059)\end{array}$ & $\begin{array}{l}-0.289 * * * \\
(0.063)\end{array}$ & $\begin{array}{l}-0.326 * * * \\
(0.065)\end{array}$ & $\begin{array}{l}-0.303 * * * \\
(0.046)\end{array}$ & $\begin{array}{l}-0.237 * * * \\
(0.049)\end{array}$ & $\begin{array}{l}-0.251 * * * \\
(0.051)\end{array}$ \\
\hline Disorderliness (NS4) & $\begin{array}{l}0.117 * * \\
(0.059)\end{array}$ & $\begin{array}{l}0.064 \\
(0.062)\end{array}$ & $\begin{array}{l}-0.007 \\
(0.065)\end{array}$ & $\begin{array}{l}0.083 * \\
(0.046)\end{array}$ & $\begin{array}{l}0.034 \\
(0.048)\end{array}$ & $\begin{array}{l}-0.026 \\
(0.051)\end{array}$ \\
\hline Harm Avoidance (HA) & $\begin{array}{l}-0.419 * * * \\
(0.064)\end{array}$ & $\begin{array}{l}-0.265^{* * *} \\
(0.066)\end{array}$ & $\begin{array}{l}-0.207 * * * \\
(0.069)\end{array}$ & $\begin{array}{l}-0.309 * * * \\
(0.048)\end{array}$ & $\begin{array}{l}-0.160 * * * \\
(0.051)\end{array}$ & $\begin{array}{l}-0.104 * \\
(0.053)\end{array}$ \\
\hline Worry/pessimism (HA1) & $\begin{array}{l}-0.299 * * * \\
(0.065)\end{array}$ & $\begin{array}{l}-0.171 * * * \\
(0.066)\end{array}$ & $\begin{array}{l}-0.134 * \\
(0.069)\end{array}$ & $\begin{array}{l}-0.202 * * * \\
(0.048)\end{array}$ & $\begin{array}{l}-0.080 \\
(0.050)\end{array}$ & $\begin{array}{l}-0.032 \\
(0.053)\end{array}$ \\
\hline Fear of uncertainty (HA2) & $\begin{array}{l}-0.373 * * * \\
(0.061)\end{array}$ & $\begin{array}{l}-0.251 * * * \\
(0.066)\end{array}$ & $\begin{array}{l}-0.190^{* * *} \\
(0.069)\end{array}$ & $\begin{array}{l}-0.294 * * * \\
(0.047)\end{array}$ & $\begin{array}{l}-0.141 * * * \\
(0.051)\end{array}$ & $\begin{array}{l}-0.087 \\
(0.054)\end{array}$ \\
\hline Shyness (HA3) & $\begin{array}{l}-0.328 * * * \\
(0.062)\end{array}$ & $\begin{array}{l}-0.214^{* * *} \\
(0.064)\end{array}$ & $\begin{array}{l}-0.173 * * * \\
(0.066)\end{array}$ & $\begin{array}{l}-0.225^{* * *} \\
(0.047)\end{array}$ & $\begin{array}{l}-0.133 * * * \\
(0.049)\end{array}$ & $\begin{array}{l}-0.095 * \\
(0.051)\end{array}$ \\
\hline Fatigability (HA4) & $\begin{array}{l}-0.277 * * * \\
(0.064)\end{array}$ & $\begin{array}{l}-0.189 * * * \\
(0.067)\end{array}$ & $\begin{array}{l}-0.141 * * \\
(0.070)\end{array}$ & $\begin{array}{l}-0.231 * * * \\
(0.049)\end{array}$ & $\begin{array}{l}-0.146^{* * * *} \\
(0.051)\end{array}$ & $\begin{array}{l}-0.110 * * \\
(0.054)\end{array}$ \\
\hline Reward Dependence (RD) & $\begin{array}{l}-0.193^{* * *} \\
(0.059)\end{array}$ & $\begin{array}{l}-0.063 \\
(0.068)\end{array}$ & $\begin{array}{l}-0.037 \\
(0.070)\end{array}$ & $\begin{array}{l}-0.252 * * * \\
(0.046)\end{array}$ & $\begin{array}{l}-0.093 * \\
(0.052)\end{array}$ & $\begin{array}{l}-0.077 \\
(0.055)\end{array}$ \\
\hline Sentimentality (RD1) & $\begin{array}{l}-0.368 * * * \\
(0.062)\end{array}$ & $\begin{array}{l}-0.184 * * * \\
(0.070)\end{array}$ & $\begin{array}{l}-0.165^{* *} \\
(0.073)\end{array}$ & $\begin{array}{l}-0.382 * * * \\
(0.048)\end{array}$ & $\begin{array}{l}-0.164 * * * \\
(0.054)\end{array}$ & $\begin{array}{l}-0.151 * * * \\
(0.057)\end{array}$ \\
\hline Attachment (RD3) & $\begin{array}{l}-0.027 \\
(0.060)\end{array}$ & $\begin{array}{l}0.046 \\
(0.065)\end{array}$ & $\begin{array}{l}0.060 \\
(0.067)\end{array}$ & $\begin{array}{l}-0.125^{* * *} \\
(0.045)\end{array}$ & $\begin{array}{l}-0.037 \\
(0.049)\end{array}$ & $\begin{array}{l}-0.017 \\
(0.051)\end{array}$ \\
\hline Dependence (RD4) & $\begin{array}{l}0.051 \\
(0.061)\end{array}$ & $\begin{array}{l}0.016 \\
(0.063)\end{array}$ & $\begin{array}{l}0.030 \\
(0.066)\end{array}$ & $\begin{array}{l}0.059 \\
(0.047)\end{array}$ & $\begin{array}{l}0.037 \\
(0.049)\end{array}$ & $\begin{array}{l}0.031 \\
(0.051)\end{array}$ \\
\hline Persistence $(\mathrm{P})$ & $\begin{array}{l}0.254 * * * \\
(0.060)\end{array}$ & $\begin{array}{l}0.133 * * \\
(0.063)\end{array}$ & $\begin{array}{l}0.071 \\
(0.065)\end{array}$ & $\begin{array}{l}0.248 * * * \\
(0.047)\end{array}$ & $\begin{array}{l}0.140 * * * \\
(0.049)\end{array}$ & $\begin{array}{l}0.073 \\
(0.051)\end{array}$ \\
\hline Controls & None & $\begin{array}{l}\text { Gender, } \\
\text { Education }\end{array}$ & All & None & $\begin{array}{l}\text { Gender, } \\
\text { Education }\end{array}$ & All \\
\hline $\mathrm{N}$ & 3291 & 3291 & 3019 & 3291 & 3291 & 3019 \\
\hline \# of Participants & 304 & 304 & 289 & 559 & 559 & 533 \\
\hline
\end{tabular}




\section{Table 7 Stock Market Participation among the High Socioeconomic Status}

The subsample here contains only those individuals with both a university degree and a managerial level occupation. The dependent variable in this logistic regression is 1 for those who were stock market participants in the period 1995 1999, or in the period 2003-2010. The TCI temperament subscale scores and socioeconomic variables are from the NFBC survey in 1997. The TCI subscale scores are standardized to mean zero and standard deviation of 1. Income is in euros. Children is the number of children in the household. The table reports the logistic regression coefficients and standard errors. $\mathrm{c}$ is the area under the receiver operator characteristic (ROC) curve. *, **, and *** denote significance at the $10 \%, 5 \%$, and $1 \%$ levels, respectively.

\begin{tabular}{lllllll}
\hline & $1995-1999$ & & & $2003-2010$ & \\
& Coef. & S.E. & M.E. & Coef. & S.E. & M.E. \\
\hline Exploratory excitability(NS1) & $0.575^{* *}$ & 0.248 & 0.082 & $0.475^{* *}$ & 0.200 & 0.088 \\
Impulsiveness (NS2) & 0.067 & 0.179 & 0.01 & 0.028 & 0.149 & 0.005 \\
Extravagance (NS3) & $-0.872^{* * *}$ & 0.207 & -0.125 & $-0.389^{* *}$ & 0.171 & -0.072 \\
Disorderliness (NS4) & -0.253 & 0.172 & -0.036 & -0.149 & 0.149 & -0.027 \\
Worry/pessimism (HA1) & 0.023 & 0.217 & 0.003 & -0.056 & 0.178 & -0.010 \\
Fear of uncertainty (HA2) & $-0.466^{*}$ & 0.242 & -0.067 & -0.192 & 0.201 & -0.035 \\
Shyness (HA3) & 0.037 & 0.231 & 0.005 & 0.119 & 0.197 & 0.022 \\
Fatigability (HA4) & -0.190 & 0.241 & -0.027 & -0.154 & 0.201 & -0.028 \\
Sentimentality (RD1) & $-0.540^{* * *}$ & 0.183 & -0.077 & $-0.531^{* * *}$ & 0.154 & -0.098 \\
Attachment (RD3) & -0.057 & 0.180 & -0.008 & -0.167 & 0.155 & -0.031 \\
Dependence (RD4) & $0.340^{* *}$ & 0.171 & 0.049 & $0.365 * *$ & 0.148 & 0.067 \\
Persistence (P) & -0.089 & 0.185 & -0.013 & $0.261 *$ & 0.156 & 0.048 \\
Female & -0.419 & 0.354 & & $-0.570^{*}$ & 0.300 & \\
Ln(Income) & $0.656^{* *}$ & 0.328 & & & & \\
Married & $-0.660^{*}$ & 0.395 & & & & \\
Children & 0.109 & 0.190 & & & & \\
Constant & $-9.442^{* * *}$ & 3.994 & & $-0.824 * * *$ & 0.247 & \\
\hline c & 0.80 & & & 0.76 & & \\
Pseudo-R2 & 0.30 & & & 0.25 & & \\
N & 308 & & & 317 & & \\
Unconditional Probability & & & 0.244 & & & \\
\hline
\end{tabular}




\section{Table 8 Personality Trait Subscales and Exiting the Market}

This test uses only those who were stock market participants in 2003-2010. The dependent variable is 1 for those individuals who permanently sold all of their holdings before Dec. 31, 2010. The TCI temperament subscale scores are from the NFBC survey in 1997. The scores are standardized to mean zero and standard deviation of 1 . The table reports the logistic regression coefficients and standard errors. $\mathrm{c}$ is the area under the receiver operator characteristic (ROC) curve. $* * *$, and $* * *$ denote significance at the $10 \%, 5 \%$, and $1 \%$ levels, respectively.

\begin{tabular}{llll}
\hline & Coef. & S.E. & M.E. \\
\hline Exploratory excitability(NS1) & $-0.258^{*}$ & 0.139 & -0.044 \\
Impulsiveness (NS2) & -0.101 & 0.121 & -0.017 \\
Extravagance (NS3) & $0.296^{* *}$ & 0.122 & 0.050 \\
Disorderliness (NS4) & $0.196^{*}$ & 0.117 & 0.033 \\
Worry/pessimism (HA1) & 0.115 & 0.135 & 0.020 \\
Fear of uncertainty (HA2) & -0.156 & 0.146 & -0.027 \\
Shyness (HA3) & -0.058 & 0.141 & -0.010 \\
Fatigability (HA4) & -0.12 & 0.151 & -0.021 \\
Sentimentality (RD1) & $0.224^{* *}$ & 0.112 & 0.038 \\
Attachment (RD3) & -0.01 & 0.121 & -0.002 \\
Dependence (RD4) & 0.008 & 0.108 & 0.001 \\
Persistence (P) & 0.044 & 0.127 & 0.007 \\
Constant & $-1.259^{* * *}$ & 0.118 & \\
\hline C & 0.64 & & \\
Pseudo-R2 & 0.05 & & \\
N & 559 & & \\
Unconditional Probability & & & 0.216 \\
\hline
\end{tabular}




\section{Appendix A Correlation Tables}

The tables show the Pearson correlations between variables. The correlation table was divided into 3 parts. Table A.1 shows the correlations between the temperament traits. TableA.2 shows the correlations between the temperament traits and the control variables. Table A.3. shows the correlations between the control variables. Pairwise deletion was used. Income has 3021 observations. All other variables have 3291 observations. Capitalized abbreviations refer to total trait scores, while lower-case abbreviations refer to subscale scores. Abbreviations are the same as those used in Table 1 and throughout the body of the paper.***, $* *$, and $*$ represent significance at the $1 \%, 5 \%$, and $10 \%$ level, respectively.

Table A.1. Correlations between temperament traits.

\begin{tabular}{|c|c|c|c|c|c|c|c|c|c|c|c|c|c|c|}
\hline & NS & ns1 & ns2 & ns3 & ns4 & HA & ha1 & ha2 & ha3 & ha4 & RD & rd1 & rd3 & rd4 \\
\hline ns1 & $0.63^{* * *}$ & & & & & & & & & & & & & \\
\hline ns2 & $0.73 * * *$ & $0.21 * * *$ & & & & & & & & & & & & \\
\hline ns3 & $0.69 * * *$ & $0.27^{* * *}$ & $0.31^{* * *}$ & & & & & & & & & & & \\
\hline ns4 & $0.61 * * *$ & $0.17^{* * *}$ & $0.36^{* * *}$ & $0.23^{* * *}$ & & & & & & & & & & \\
\hline HA & $-0.27 * * *$ & $-0.42 * * *$ & $-0.09 * * *$ & $-0.09 * * *$ & $-0.12 * * *$ & & & & & & & & & \\
\hline ha1 & $-0.16 * * *$ & $-0.26 * * *$ & $-0.05^{* * *}$ & $-0.06 * * *$ & $-0.04^{* *}$ & $0.79 * * *$ & & & & & & & & \\
\hline ha2 & $-0.28 * * *$ & $-0.34 * * *$ & $-0.14 * * *$ & $-0.10 * * *$ & $-0.17 * * *$ & $0.76 * * *$ & $0.46^{* * *}$ & & & & & & & \\
\hline ha3 & $-0.27 * * *$ & $-0.41 * * *$ & $-0.06 * * *$ & $-0.12 * * *$ & $-0.12 * * *$ & $0.80 * * *$ & $0.49 * * *$ & $0.50^{* * *}$ & & & & & & \\
\hline ha4 & $-0.13 * * *$ & $-0.30 * * *$ & -0.02 & 0.02 & -0.02 & $0.74 * * *$ & $0.47^{* * *}$ & $0.44 * * *$ & $0.44 * * *$ & & & & & \\
\hline RD & $0.18^{* * *}$ & $0.28^{* * *}$ & 0.00 & $0.20^{* * *}$ & -0.02 & $-0.01 * * *$ & 0.03 & $0.09 * * *$ & $-0.14 * * *$ & -0.01 & & & & \\
\hline rd1 & $0.09 * * *$ & $0.08^{* * *}$ & $0.04^{* *}$ & $0.10^{* * *}$ & 0.02 & $0.15^{* * *}$ & $0.15^{* * *}$ & $0.20 * * *$ & $0.05^{* * *}$ & $0.07^{* * *}$ & $0.7^{* * *}$ & & & \\
\hline $\mathrm{rd} 3$ & $0.23 * * *$ & $0.36^{* * *}$ & 0.01 & $0.22^{* * *}$ & 0.00 & $-0.23 * * *$ & $-0.15^{* * *}$ & $-0.09 * * *$ & $-0.32 * * *$ & $-0.14 * * *$ & $0.75^{* * *}$ & $0.21 * * *$ & & \\
\hline $\mathrm{rd4}$ & $0.00 * * *$ & $0.11^{* * *}$ & $-0.09 * * *$ & $0.05^{* * *}$ & $-0.09 * * *$ & $0.08 * * *$ & $0.08^{* * *}$ & $0.08^{* * *}$ & 0.02 & $0.07^{* * *}$ & $0.53^{* * *}$ & $0.07 * * *$ & $0.21 * * *$ & \\
\hline $\mathbf{P}$ & $-0.06 * * *$ & $0.15^{* * *}$ & $-0.12 * * *$ & $-0.13 * * *$ & $-0.06 * * *$ & $-0.28 * * *$ & $-0.11 * * *$ & $-0.24 * * *$ & $-0.17 * * *$ & $-0.36 * * *$ & -0.01 & $0.08 * * *$ & -0.01 & $-0.12 * * *$ \\
\hline
\end{tabular}


Table A.2. Correlations between temperament traits and controls.

\begin{tabular}{|c|c|c|c|c|c|c|c|c|c|c|c|}
\hline & Female & Income & Married & Children & Basic Ed. & Secondary Ed. & University & Worker & Entrepreneur & Manager & Participation \\
\hline ns1 & $0.08^{* * *}$ & $0.06 * * *$ & 0 & -0.02 & $-0.08 * * *$ & $0.03 *$ & $0.08^{* * *}$ & $-0.04 * *$ & 0.01 & $0.10 * * *$ & $0.03 *$ \\
\hline ns2 & $0.09 * * *$ & 0.01 & $-0.03 *$ & 0.02 & 0 & 0.01 & -0.01 & 0.02 & 0.02 & 0.02 & -0.01 \\
\hline ns3 & $0.16^{* * *}$ & -0.01 & $-0.07 * * *$ & -0.03 & -0.03 & $0.04 * *$ & -0.03 & 0.01 & $-0.04 * *$ & 0.02 & $-0.12 * * *$ \\
\hline HA & $0.18^{* * *}$ & $-0.13^{* * *}$ & -0.03 & 0.03 & $0.07^{* * *}$ & 0.01 & $-0.12^{* * *}$ & $0.06^{* * *}$ & $-0.09 * * *$ & $-0.13^{* * *}$ & $-0.11^{* * *}$ \\
\hline ha1 & $0.14^{* * *}$ & $-0.10 * * *$ & -0.01 & $0.04 * *$ & $0.06^{* * *}$ & 0 & $-0.08^{* * *}$ & $0.04 * *$ & $-0.04 * * *$ & $-0.11 * * *$ & $-0.07 * * *$ \\
\hline ha2 & $0.27^{* * *}$ & $-0.07 * * *$ & $0.03 *$ & $0.06^{* * *}$ & 0.01 & $0.04^{* *}$ & $-0.08^{* * *}$ & $0.03 *$ & $-0.07^{* * *}$ & $-0.08 * * *$ & $-0.11 * * *$ \\
\hline ha3 & $0.03 * *$ & $-0.12 * * *$ & $-0.05^{* * *}$ & 0 & $0.12 * * *$ & $-0.04 * *$ & $-0.12 * * *$ & $0.08 * * *$ & $-0.06 * * *$ & $-0.14 * * *$ & $-0.08 * * *$ \\
\hline rd3 & $0.24 * * *$ & $0.07^{* * *}$ & $0.11^{* * *}$ & $0.11^{* * *}$ & $-0.09 * * *$ & $0.08^{* * *}$ & 0.03 & 0.01 & $-0.03 *$ & $0.04 * *$ & $-0.05^{* * *}$ \\
\hline rd4 & $0.03 *$ & $0.07^{* * *}$ & $0.10^{* * *}$ & 0.02 & $-0.11 * * *$ & $0.09 * * *$ & $0.05^{* * *}$ & $0.03 *$ & -0.02 & $0.08^{* * *}$ & 0.02 \\
\hline $\mathbf{P}$ & $-0.12^{* * *}$ & $0.06^{* * *}$ & 0.02 & $-0.04 * *$ & $-0.06 * * *$ & 0.01 & $0.09 * * *$ & $-0.09 * * *$ & $0.09 * * *$ & $0.09 * * *$ & $0.09 * * *$ \\
\hline
\end{tabular}


Table A.3. Correlations between control variables and the participation dummy.

\begin{tabular}{|c|c|c|c|c|c|c|c|c|c|c|}
\hline & Female & Income & Married & Children & Basic Ed. & $\begin{array}{l}\text { Second. } \\
\text { Ed. }\end{array}$ & University & Worker & Entrepreneur & Manager \\
\hline Income & 0.03 & & & & & & & & & \\
\hline Children & $0.14^{* * *}$ & $0.07^{* * *}$ & $0.49 * * *$ & & & & & & & \\
\hline Basic Ed. & $-0.18 * * *$ & $-0.16 * * *$ & $-0.06 * * *$ & $0.13^{* * *}$ & & & & & & \\
\hline University & -0.02 & $0.18^{* * *}$ & $0.05^{* * *}$ & $-0.10 * * *$ & $-0.42 * * *$ & $-0.26 * * *$ & & & & \\
\hline Worker & $0.03 *$ & $-0.03 *$ & 0 & $0.06 * * *$ & $0.23^{* * *}$ & 0.01 & $-0.35^{* * *}$ & & & \\
\hline Entrepr. & $-0.11^{* * *}$ & 0.01 & 0.02 & 0.01 & $0.06^{* * *}$ & $-0.04 * *$ & $-0.03^{*}$ & $-0.30 * * *$ & & \\
\hline
\end{tabular}




\section{Appendix B}

\section{Table B.1 Personality Traits and Stock Market Participation 1995-1999}

The dependent variable in these logistic regressions is 1 for those who were stock market participants in the period 2003-2010. The TCI temperament scores and socioeconomic variables are from the NFBC survey in 1997. The TCI scores are standardized to mean zero and standard deviation of 1 . Income is in euros. Children is the number of children in the household. Education variables are dummy variables representing the highest level of education achieved; the omitted class is basic education. Occupations are dummy variables; the omitted classes are workers and others. Panel A reports the coefficients and standard errors. $\mathrm{c}$ is the area under the receiver operator characteristic (ROC) curve. *, **, and $* * *$ denote significance at the $10 \%, 5 \%$, and $1 \%$ levels, respectively. Panel B reports the average of the marginal effects calculated for each observation

Panel A: Coefficients and Standard Errors

\begin{tabular}{|c|c|c|c|c|c|c|c|c|}
\hline & \multicolumn{2}{|l|}{ Model 1} & \multicolumn{2}{|l|}{ Model 2} & \multicolumn{2}{|l|}{ Model 3} & \multicolumn{2}{|l|}{ Model 4} \\
\hline & Coef. & S.E. & Coef. & S.E. & Coef. & S.E. & Coef. & S.E. \\
\hline Novelty Seeking NS & -0.057 & 0.065 & -0.020 & 0.066 & -0.031 & 0.068 & -0.104 & 0.071 \\
\hline Harm Avoidance HA & $-0.389 * * *$ & 0.070 & $-0.327 * * *$ & 0.071 & $-0.261 * * *$ & 0.073 & $-0.245^{* * *}$ & 0.077 \\
\hline Reward Dependence RD & $-0.186^{* * * *}$ & 0.061 & -0.080 & 0.066 & -0.076 & 0.069 & -0.034 & 0.072 \\
\hline Persistence P & $0.138 * *$ & 0.064 & $0.121^{*}$ & 0.065 & 0.060 & 0.067 & 0.000 & 0.069 \\
\hline Female & & & $-0.617 * * *$ & 0.136 & $-0.845^{* * *}$ & 0.144 & $-0.712 * * *$ & 0.151 \\
\hline Ln(Income) & & & & & & & $0.384 * * *$ & 0.128 \\
\hline Secondary Ed. & & & & & $1.003 * * *$ & 0.153 & $0.870 * * *$ & 0.166 \\
\hline University Ed. & & & & & $1.773 * * *$ & 0.162 & $1.327 * * *$ & 0.211 \\
\hline Married & & & & & & & $-0.316 * *$ & 0.16 \\
\hline Children & & & & & & & $-0.180 * *$ & 0.072 \\
\hline Manager & & & & & & & $0.482 * * *$ & 0.175 \\
\hline Entrepreneur & & & & & & & $0.685^{* * *}$ & 0.238 \\
\hline Constant & $-2.377 * * *$ & 0.065 & $-2.046 * * *$ & 0.093 & $-2.629 * * *$ & 0.122 & $-6.976 * * *$ & 1.511 \\
\hline $\mathrm{c}$ & 0.63 & & 0.65 & & 0.73 & & 0.75 & \\
\hline Pseudo-R2 & 0.05 & & 0.05 & & 0.13 & & 0.16 & \\
\hline $\mathrm{N}$ & 3291 & & 3291 & & 3291 & & 3019 & \\
\hline
\end{tabular}

Panel B: Marginal Effects

\begin{tabular}{lllll}
\hline & Model 1 & Model 2 & Model 3 & Model 4 \\
\hline Novelty Seeking NS & -0.005 & -0.002 & -0.002 & -0.008 \\
Harm Avoidance HA & -0.032 & -0.027 & -0.020 & -0.019 \\
Reward Dependence RD & -0.015 & -0.007 & -0.006 & -0.003 \\
Persistence P & 0.011 & 0.010 & 0.005 & 0.000 \\
\hline Unconditional Probability & 0.092 & 0.092 & 0.092 & 0.096 \\
\hline
\end{tabular}




\section{Table B.2 Personality Subscales and Stock Market Participation 1995-1999}

The dependent variable in these logistic regressions is 1 for those who were stock market participants in the period 2003-2010. The TCI temperament subscale scores and socioeconomic variables are from the NFBC survey in 1997. The TCI subscale scores are standardized to mean zero and standard deviation of 1 . Income is in euros. Children is the number of children in the household. Education variables are dummy variables representing the highest level of education achieved; the omitted class is basic education. Occupations are dummy variables; the omitted classes are workers and others. Panel A reports the coefficients and standard errors. $\mathrm{c}$ is the area under the receiver operator characteristic (ROC) curve. *, **, and *** denote significance at the 10\%, 5\%, and 1\% levels, respectively. Panel B reports the average of the marginal effects calculated for each observation. 
Table B.2.

Panel A. Coefficients and Standard Errors

\begin{tabular}{|c|c|c|c|c|c|c|c|c|}
\hline & \multicolumn{2}{|l|}{ Model 1} & \multicolumn{2}{|l|}{ Model 2} & \multicolumn{2}{|l|}{ Model 3} & \multicolumn{2}{|l|}{ Model 4} \\
\hline & Coef. & S.E. & Coef. & S.E. & Coef. & S.E. & Coef. & S.E. \\
\hline Exploratory excitability(NS1) & $0.183^{* *}$ & 0.08 & $0.198 * *$ & 0.081 & $0.191 * *$ & 0.083 & $0.175^{* *}$ & 0.087 \\
\hline Impulsiveness (NS2) & $0.130 *$ & 0.07 & $0.152 * *$ & 0.071 & $0.163 * *$ & 0.072 & $0.157 * *$ & 0.075 \\
\hline Extravagance (NS3) & $-0.470 * * *$ & 0.07 & $-0.451 * * *$ & 0.070 & $-0.457 * * *$ & 0.073 & $-0.487 * * *$ & 0.076 \\
\hline Disorderliness (NS4) & $0.131^{*}$ & 0.067 & $0.115^{*}$ & 0.067 & 0.059 & 0.070 & -0.017 & 0.073 \\
\hline Worry/pessimism (HA1) & -0.103 & 0.08 & -0.094 & 0.080 & -0.041 & 0.082 & -0.020 & 0.086 \\
\hline Fear of uncertainty (HA2) & $-0.137 *$ & 0.08 & -0.084 & 0.082 & -0.141 & 0.087 & -0.139 & 0.09 \\
\hline Shyness (HA3) & $-0.162 * *$ & 0.082 & $-0.177 * *$ & 0.082 & -0.101 & 0.085 & -0.105 & 0.088 \\
\hline Fatigability (HA4) & 0.044 & 0.083 & 0.047 & 0.083 & 0.027 & 0.087 & 0.021 & 0.091 \\
\hline Sentimentality (RD1) & $-0.331 * * *$ & 0.068 & $-0.257 * * *$ & 0.072 & $-0.184 * *$ & 0.074 & $-0.160 * *$ & 0.077 \\
\hline Attachment (RD3) & -0.010 & 0.073 & 0.017 & 0.073 & 0.027 & 0.075 & 0.066 & 0.077 \\
\hline Dependence (RD4) & $0.171 * * *$ & 0.065 & $0.154 * *$ & 0.065 & 0.097 & 0.068 & 0.093 & 0.071 \\
\hline Persistence (P) & $0.178 * *$ & 0.071 & $0.158 * *$ & 0.072 & 0.064 & 0.074 & -0.007 & 0.077 \\
\hline Female & & & $-0.435 * * *$ & 0.147 & $-0.702 * * *$ & 0.154 & $-0.573 * * *$ & 0.162 \\
\hline Ln(Income) & & & & & & & $0.354 * * *$ & 0.13 \\
\hline Secondary Ed. & & & & & $0.968 * * *$ & 0.156 & $0.833 * * *$ & 0.169 \\
\hline University Ed. & & & & & $1.711 * * *$ & 0.166 & $1.288 * * *$ & 0.216 \\
\hline Married & & & & & & & $-0.332 * *$ & 0.163 \\
\hline Children & & & & & & & $-0.191 * * *$ & 0.073 \\
\hline Manager & & & & & & & $0.469 * * *$ & 0.179 \\
\hline Entrepreneur & & & & & & & $0.680 * * *$ & 0.242 \\
\hline Constant & $-2.498 * * *$ & 0.072 & $-2.256 * * *$ & 0.105 & $-2.787 * * *$ & 0.131 & $-6.752 * * *$ & 1.526 \\
\hline $\mathrm{c}$ & 0.70 & & 0.71 & & 0.76 & & 0.77 & \\
\hline Pseudo-R2 & 0.09 & & 0.10 & & 0.16 & & 0.19 & \\
\hline $\mathrm{N}$ & 3291 & & 3291 & & 3291 & & 3019 & \\
\hline
\end{tabular}

Panel B. Marginal Effects

\begin{tabular}{lllll}
\hline & Model 1 & Model 2 & Model 3 & Model 4 \\
\hline Exploratory excitability(NS1) & 0.015 & 0.016 & 0.014 & 0.013 \\
Impulsiveness (NS2) & 0.010 & 0.012 & 0.012 & 0.012 \\
Extravagance (NS3) & -0.038 & -0.036 & -0.035 & -0.038 \\
Disorderliness (NS4) & 0.010 & 0.009 & 0.004 & -0.001 \\
Worry/pessimism (HA1) & -0.008 & -0.007 & -0.003 & -0.002 \\
Fear of uncertainty (HA2) & -0.011 & -0.007 & -0.011 & -0.011 \\
Shyness (HA3) & -0.013 & -0.014 & -0.008 & 0.008 \\
Fatigability (HA4) & 0.004 & 0.004 & 0.002 & -0.002 \\
Sentimentality (RD1) & -0.026 & -0.020 & -0.014 & 0.005 \\
Attachment (RD3) & -0.001 & 0.001 & 0.002 & 0.007 \\
Dependence (RD4) & 0.014 & 0.012 & 0.007 & -0.001 \\
Persistence (P) & 0.014 & 0.013 & 0.005 & 0.096 \\
\hline Unconditional Probability & 0.092 & 0.092 & 0.092 & \\
\hline
\end{tabular}

